\title{
A p53-Phosphoinositide Signalosome Regulates Nuclear Akt Activation
}

Mo Chen ${ }^{1}$, Suyong Choi ${ }^{1}$, Tianmu Wen ${ }^{1}$, Changliang Chen ${ }^{1,2}$, Narendra Thapa ${ }^{1}$, Vincent L. Cryns ${ }^{2,3, *}$, and Richard A. Anderson ${ }^{1,3, *}$

1 University of Wisconsin-Madison, School of Medicine and Public Health; 1300 University Avenue, Madison, WI 53706, USA

${ }^{2}$ Department of Medicine, University of Wisconsin Carbone Cancer Center, University of Wisconsin-Madison, School of Medicine and Public Health; 1111 Highland Avenue, Madison, WI 53705, USA

${ }^{3}$ These authors contributed equally to this work

*Correspondence: raanders@wisc.edu (R.A.A.); vlcryns@medicine.wisc.edu (V.L.C.)

\section{Abstract}

The tumor suppressor p53 and the phosphoinositide 3-kinase (PI3K)-Akt pathway have fundamental roles in regulating cell growth, apoptosis and are frequently mutated in cancer. Here, we show that genotoxic stress induces nuclear Akt activation by a p53dependent mechanism that is independent from the canonical membrane-localized PI3KAkt pathway. Upon genotoxic stress a nuclear p53-PI3,4,5 $\mathrm{P}_{3}$ complex is generated in regions devoid of membranes by a nuclear $\mathrm{PI}$ K, and this complex recruits all the kinases required to activate Akt and phosphorylate FOXOs, inhibiting DNA damage-induced apoptosis. Wild-type p53 activates nuclear Akt in an on/off fashion upon stress, whereas mutant p53 stimulates high basal Akt activity, indicating a fundamental difference. The nuclear p53-phosphoinositide signalosome is distinct from the canonical membranelocalized pathway and insensitive to PI3K inhibitors currently in the clinic, underscoring its therapeutic relevance.

\section{Key words}

p53; Akt; PI3K; phosphoinositide; PI4,5P2; PI3,4,5P $;$; nucleus

\section{In brief}

p53 assembles a PI3K-Akt pathway that regulates nuclear Akt activation independent of the canonical pathway on membranes. 


\section{INTRODUCTION}

Phosphoinositide (PI) 3-kinase (PI3K)-mediated generation of $\mathrm{PI}, 4,5 \mathrm{P}_{3}$ downstream of membrane receptors activates the serine/threonine protein kinase Akt, a critical regulator of cell growth, survival, and metabolism, and this pathway is frequently hyperactivated in cancer ${ }^{1-3}$. In the canonical membrane-localized PI3K-Akt pathway, $\mathrm{PI} 3,4,5 \mathrm{P}_{3}$ is a required binding lipid that recruits Akt and PDK1 to membranes via their pleckstrin homology $(\mathrm{PH})$ domains $^{3,4}$ and this enables active PDK1 to phosphorylate T308 on $\mathrm{Akt}^{5}$. The subsequent phosphorylation of Akt primarily by mTORC2 on S473 stimulates full Akt activity ${ }^{3,6}$. Active Akt is present in the cytoplasm ${ }^{7}$ and nucleus ${ }^{8}$. There are reports indicating translocation of active Akt from the cytoplasm to the nucleus ${ }^{9-11}$ and de novo nuclear activation of Akt ${ }^{12-14}$. However, the underlying mechanisms of nuclear Akt activation and the functional role of Akt in the nucleus are poorly understood.

The tumor suppressor p53 maintains genome integrity in response to cellular stress and is the most commonly mutated gene in cancer ${ }^{15,16}$. We have previously demonstrated that p53 interacts with the type I phosphatidylinositol phosphate (PIP) kinase PIPKIa (encoded by PIP5K1A), which transfers its product PI4,5P 2 to the $\mathrm{C}$-terminal domain of p53. The p53-PI4,5P 2 complex then recruits small heat shock proteins (sHSPs), which bind p53 and stabilize the protein ${ }^{17}$, but the functions of the p53-PI4,5P 2 complex are unknown. Intriguingly, the nuclear PI3K inositol polyphosphate multikinase (IPMK) ${ }^{18}$ and the 3-phosphatase PTEN ${ }^{19}$ also interact with $\mathrm{p53}$. Moreover, IPMK and PTEN regulate the interconversion of $\mathrm{PI} 4,5 \mathrm{P}_{2}$ and $\mathrm{PI} 3,4,5 \mathrm{P}_{3}$-bound forms of the nuclear receptor steroidogenic factor 1 (SF-1), which control its transcriptional activity ${ }^{20,21}$. Additionally, Akt was identified as a potential p53 interactor ${ }^{22}$. These diverse findings suggest that p53 
may be systematically targeted by multiple phosphoinositide kinases and phosphatases to produce $\mathrm{p53}-\mathrm{PI} 3,4,5 \mathrm{P}_{3}$ and regulate Akt activation in the nucleus independently of the canonical membrane-localized pathway.

Here, we demonstrate that genotoxic stress induces nuclear Akt activation by a p53dependent mechanism. p53-PI4,5 $\mathrm{P}_{2}$ is converted to $\mathrm{p} 53-\mathrm{PI}, 4,5 \mathrm{P}_{3}$ in response to cellular stress by the nuclear PI3K inositol polyphosphate multikinase (IPMK), and the 3phosphatase $\mathrm{PTEN}$ reverses this reaction. $\mathrm{PI}, 4,5 \mathrm{P}_{3}$ binding stimulates the assembly of PDK1, mTORC2, Akt, and FOXOs on p53, leading to nuclear activation of Akt and phosphorylation of FOXOs. Inhibition of PIPKIa or IPMK, but not class I PI3Ks, disrupts p53-PI3,4,5 $\mathrm{P}_{3}$ formation and nuclear Akt activation. The nuclear p53-PI3,4,5 $\mathrm{P}_{3}-\mathrm{Akt}$ complex is regulated by cellular stress and attenuates DNA damage, invasion and cell death. Our findings establish a PI3K-Akt pathway that dynamically assembles on p53 to control nuclear Akt activation. This p53-phosphoinositide signalosome is independent of the canonical membrane-localized PI3K-Akt pathway, underscoring its therapeutic relevance.

\section{RESULTS}

\section{p53 interacts with nuclear Akt and regulates its activation}

Although Akt is activated in the nucleus by genotoxic stress and active Akt is observed in the nucleus of cancer cells $8,12,13,23$, the mechanisms of nuclear Akt activation and its function remain enigmatic. To gain mechanistic insights into nuclear Akt activation, we examined the subcellular distribution of phosphorylated Akt under normal and stressed conditions by immunofluorescent (IF) staining. Consistent with prior reports ${ }^{13,}{ }^{14}$, 
genotoxic stress increased the nuclear levels of two active Akt phospho-forms (pAkt ${ }^{\top 308}$ and $\mathrm{pAkt}^{\mathrm{S473}}$ ) in the membrane-free nucleoplasm (Fig. 1a,b). Given the critical role of class I PI3K-mediated $\mathrm{PI}, 4,5 \mathrm{P}_{3}$ production in Akt activation in the canonical membranelocalized PI3K-Akt pathway1,2, we postulated a functional role of class I PI3Ks in stressinduced nuclear Akt activation. However, the increase in nuclear pAkt $^{\mathrm{S} 473}$ levels by cisplatin treatment was not attenuated by the class I PI3K inhibitors alpelisib and buparlisib $^{24}$ at concentrations that suppressed EGF-stimulated Akt activation (Extended Data Fig. 1a-c), indicating that nuclear Akt activation is independent of the canonical PI3K-Akt pathway.

Akt was identified as a potential p53 interacting protein ${ }^{22}$ and p53 forms a stable nuclear complex with the PIP 5-kinase PIPKIa and the $\mathrm{PI}, 4,5 \mathrm{P}_{3}$ precursor $\mathrm{PI}, 5 \mathrm{P}_{2}{ }^{17}$, suggesting a link between nuclear Akt and p53. Consistently, cisplatin increased the colocalization of the active Akt isoforms (pAkt ${ }^{\top 308}$ and $\left.p A k t^{S 473}\right)$ with mutant $p 53^{R 280 K}$ (Fig. 1a-c). Multiple cell stressors augmented nuclear Akt activation and colocalization of pAkt ${ }^{S 473}$ with mutant p53 (Extended Data Fig. 1d-g). Stimulated-depletion-emission (STED) microscopy confirmed that genotoxic stress enhanced the colocalization of

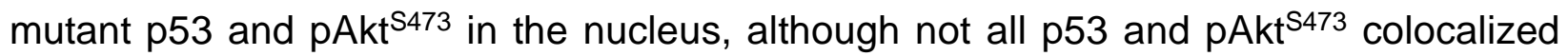
(Fig. 1d-f). Genotoxic stress also increased nuclear levels of wild-type 53 and pAkt ${ }^{\text {S473and }}$ their nuclear colocalization, but there was no stress-induced cytosolic colocalization of p53 and pAkt ${ }^{S 473}$ (Extended Data Fig. 1h-n). Cisplatin enhanced the association of both wild-type and mutant $\mathrm{p} 53^{\mathrm{R} 280 \mathrm{~K}}$ with total Akt, $\mathrm{pAkt}{ }^{\mathrm{T30}}$, and $\mathrm{pAkt} \mathrm{S}^{\mathrm{S} 33}$ in the nucleus as quantified by proximity ligation assay (PLA) (Fig. 1g and Extended Data Fig. 2a). Multiple cellular stressors increased the levels of the p53-pAkt ${ }^{S 43}$ complex in the nucleus 
(Extended Data Fig. 2b). The mutant p53(R280K)-pAkt complexes identified by PLA localized to the non-membranous nucleoplasm and were stimulated by genotoxic stress (Fig. 1h). 3D section images and reconstitution confirmed the nuclear localization of the p53-pAkt ${ }^{S 473}$ complex to membrane-free regions (Extended Data Fig. 2c and Extended Data Videos 1-2). The interactions of both wild-type and mutant $p 53^{\mathrm{R} 280 \mathrm{~K}}$ with Akt were also detected by co-IP and enhanced by cisplatin (Fig. 1i-k and Extended Data Fig. 2d). Multiple stress stimuli augmented mutant p53 binding to Akt (Fig. 1I). Direct binding of recombinant p53 and Akt1 proteins was detected by p53 IP (Fig. 1m). Additionally, the interaction of p53 with Akt1 was quantified by microscale thermophoresis (MST). Akt1 and p53 directly interacted with $10 \pm 2$ nM affinity (Extended Data Table 1). To determine the functional role of $\mathrm{p53}$ in nuclear Akt activation, we silenced p53 with specific siRNAs and measured nuclear mutant $\mathrm{p} 53^{\mathrm{R} 280 \mathrm{~K}}$ and $\mathrm{pAkt} \mathrm{t}^{\mathrm{4} 73}$ levels. Quantification showed a loss of nuclear pAkt ${ }^{S 43}$ upon p53 knockdown (KD) (Fig. 1n,o). Together, these data indicate that p53 interacts with Akt in the nucleus and promotes its activation.

\section{p53 recruits upstream Akt-activating kinases}

To elucidate the mechanisms by which p53 activates nuclear Akt, we examined the association of p53 with the upstream kinases required for cytosolic Akt activation. Consistent with the effects of genotoxic stress on the nuclear localization of Akt, cisplatin increased the nuclear levels of active and nuclear-retained PDK1 (pPDK1 ${ }^{\text {s241 }}$ and pPDK1 ${ }^{\text {S396 }}$, respectively) ${ }^{25,26}$ and increased their colocalization with mutant p53 ${ }^{\mathrm{R} 280 \mathrm{~K}}$ (Fig. $2 a-c)$. Cisplatin enhanced the association of both wild-type and mutant $p 53^{\mathrm{R} 280 \mathrm{~K}}$ with nuclear PDK1 (total PDK1, pPDK1 ${ }^{\text {s241, and pPDK1 }}{ }^{\text {s396}}$ ) and the Sin1 subunit of mTORC2, which contains a PI3,4,5 $\mathrm{P}_{3}$-specific $\mathrm{PH}$ domain ${ }^{27}$, as quantified by PLA (Fig. 2d,e and 
Extended Data Fig. 3a). The p53-pPDK1 and p53-Sin1 complexes identified by PLA localized to the non-membranous nucleoplasm and were stimulated by genotoxic stress (Fig. 2f). The interaction of both wild-type and mutant $p 53^{R 280 K}$ with PDK1 and Sin1 was also detected by co-IP and stimulated by genotoxic stress (Fig. 2g-j and Extended Data

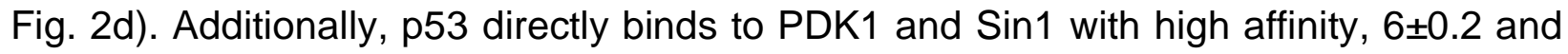
$20 \pm 1$ nM, respectively, when quantified by MST (Extended Data Table 1). Collectively, these data establish a robust, stress-induced association of wild-type and mutant p53 with Akt and its activating kinases in the nucleus (Fig. 2k).

\section{The nuclear p53-Akt complex targets FOXOs}

Akt phosphorylates multiple downstream effectors, including tuberous sclerosis complex 2 (TSC2), glycogen synthase kinase (GSK3), and members of the forkhead box O (FOXO) family2. Among these targets, FOXOs are reported to also have direct functional interactions with $\mathrm{p} 53^{28-30}$. FOXOs directly bind $\mathrm{p} 53^{29}$ and $\mathrm{p} 53$ regulates MDM2 ubiquitination and degradation of $\mathrm{FOXOs}^{30}$. The FOXO family, including FOXO1, FOXO3, FOXO4, and FOXO6 in humans, regulate cell senescence and apoptosis in response to genotoxic stress and other stimuli3, ${ }^{31}$. Akt phosphorylates FOXO proteins at three residues (Fig. 3a), resulting in the nuclear exclusion and degradation of FOXOs to promote cell survival ${ }^{3}$. FOXO1/3, FOXO fragments and phosphorylated forms co-IP'ed with Akt and mutant $\mathrm{p} 53^{\mathrm{R} 280 \mathrm{~K}}$ as intact proteins and also proteolytic fragments that were increased by cisplatin (Fig. 3b-d).

Wild-type and mutant p53 colocalized with nuclear pFOXO3 ${ }^{\mathrm{S25}}$ and their colocalization was enhanced by genotoxic stress (Fig. 3e,f). In addition, p53 associated with FOXO1/3 
and their phosphorylated forms in the membrane-free nucleoplasm in a stress-regulated manner (Fig. 3g,h and Extended Data Fig. 3b). Functionally, KD of mutant p53 diminished nuclear pFOXO3 ${ }^{\mathrm{S} 253}$ levels (Fig. 3i,j). These findings indicate that the p53-Akt complex recruits and phosphorylates FOXOs in the nucleus, thereby underscoring the functional role of this complex in nuclear Akt and p53 signaling.

\section{p53 binds and forms a stable complex with $\mathrm{PI}, 4,5 \mathrm{P}_{3}$}

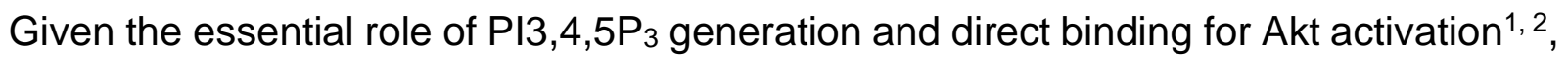
we postulated that stress-regulated phosphoinositide linkage on p53 may serve as a nuclear signal to recruit and activate Akt in the nucleus. As we have demonstrated that $\mathrm{PI} 4,5 \mathrm{P}_{2}$ forms a stable complex with $\mathrm{p} 53^{17}$, we determined if $\mathrm{PI}, 4,5 \mathrm{P}_{3}$ also associated with p53. The $\mathrm{Pl} 4,5 \mathrm{P}_{2}$ and $\mathrm{PI}_{3}, 4,5 \mathrm{P}_{3}$ epitopes were detected by fluorescent immunoblotting (IB) of FLAG-immunoprecipitated (IP), ectopically expressed wild-type and mutant $p 53^{175 \mathrm{H}}$, and the interaction of both $\mathrm{Pl}, 5 \mathrm{P}_{2}$ and $\mathrm{PI}, 4,5 \mathrm{P}_{3}$ with mutant p53 $3^{\mathrm{R} 175 \mathrm{H}}$ was blocked by the PIPKla inhibitor ISA-2011B $\mathrm{B}^{32}$ (Fig. 4a). PI4,5P 2 and $\mathrm{PI}, 4,5 \mathrm{P}_{3}$ interacted constitutively with diverse mutant p53 proteins and with wild-type p53 in response to cisplatin treatment in all cancer cell lines assayed (Fig. 4b). PI3,4,5 $\mathrm{P}_{3}$ binding to mutant $\mathrm{p} 53^{\mathrm{R} 280 \mathrm{~K}}$ was enhanced by cisplatin treatment and abolished by the PIPKIa inhibitor ISA-2011B ${ }^{32}$, but significantly not by the class I PI3K inhibitors alpelisib and buparlisib (Fig. 4c).

Cisplatin treatment increased nuclear $\mathrm{PI}, 4,5 \mathrm{P}_{3}$ levels and $\mathrm{PI}, 4,5 \mathrm{P}_{3}$ colocalization with mutant p53 ${ }^{R 280 K}$ as determined by immunofluorescence (IF) (Extended Data Fig. 4a-c). PLA revealed that $\mathrm{PI}, 5 \mathrm{P}_{2}$ and $\mathrm{PI}, 4,5 \mathrm{P}_{3}$ associated selectively with cisplatin-activated 
wild-type p53, while these phosphoinositides are associated constitutively with mutant p53 and these associations were enhanced by multiple cellular stressors (Extended Data Fig. 4d-h). The p53-PI3,4,5P 3 complexes were abolished by ISA-2011B but not by alpelisib and buparlisib (Extended Data Fig. 4i,j). The p53-PI4,5 $\mathrm{P}_{2}$ and p53-PI3,4,5 $\mathrm{P}_{3}$ complexes were localized in the nucleoplasm in regions distinct from nuclear membranes (Fig. 4d,e). 3D section images further confirmed the nuclear localization of the p53$\mathrm{PI}, 4,5 \mathrm{P}_{3}$ complexes in membrane-free regions (Extended Data Fig. 4k). The interaction

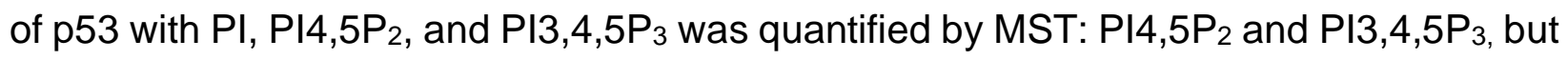
not PI, bound to recombinant p53 (Extended Data Table 1). These data indicate that $\mathrm{PI} 4,5 \mathrm{P}_{2}$ and $\mathrm{PI}, 4,5 \mathrm{P}_{3}$ form a stable nuclear complex with stress-activated wild-type and mutant p53 that is dependent on PIPKla and insensitive to class I PI3K inhibitors.

\section{IPMK and PTEN regulate the interconversion of nuclear p53-PI complexes}

The nuclear PI3K IPMK and the 3-phosphatase PTEN associate with $\mathrm{p53}{ }^{18,19}$ and we confirmed the interactions of IPMK and PTEN with stress-induced wild-type and mutant p53 by co-IP (Fig. 4f,g). IF staining revealed that genotoxic stress enhanced the content of nuclear IPMK and PTEN and their colocalization with p53 (Extended Data Fig. 5a-g). Both IPMK and PTEN associated with stress-activated wild-type p53 and mutant p53 ${ }^{\text {R280K }}$ in the nucleus in regions distinct from the nuclear membrane as determined by PLA (Fig. 4d,e and Extended Data Fig. 5h-j). IPMK and PTEN direct binding to p53 and this was quantified (Extended Data Table 1). To determine the functional role of PIPKIa, IPMK, and PTEN on p53-PI4,5 $\mathrm{P}_{2} / \mathrm{PI}, 4,5 \mathrm{P}_{3}$ complex formation, we silenced the expression of each enzyme individually with specific siRNAs and then quantified cellular content of mutant p53 ${ }^{\text {R280K }}$-PI4,5P2/PI3,4,5P3 complexes by PLA (Fig. 4h,i and Extended Data Fig. 
5k,I). PIPKla knockdown prevented the formation of the p53-PI4,5 $\mathrm{P}_{2}$ and $\mathrm{p} 53-\mathrm{PI}, 4,5 \mathrm{P}_{3}$ complexes. IPMK silencing inhibited the formation of p53-PI3,4,5 $\mathrm{P}_{3}$ complexes while


complexes, consistent with its 3-phosphatase activity, and disrupted p53-PI4,5 2 complex formation. These data indicate that IPMK and PTEN dynamically regulate the interconversion of p53-PI4,5 $\mathrm{P}_{2}$ and $\mathrm{p} 53-\mathrm{PI}, 4,5 \mathrm{P}_{3}$ complexes downstream of PIPKIa generation of $\mathrm{Pl} 4,5 \mathrm{P}_{2}$ (Fig. 4j).

\section{The p53-PI3,4,5 $\mathrm{P}_{3}$ complex recruits and activates the nuclear Akt pathway}

$\mathrm{PDK} 1, \operatorname{Sin} 1$ and $\mathrm{Akt}$ are all $\mathrm{PI}, 4,5 \mathrm{P}_{3}$ effectors that require binding to $\mathrm{PI}, 4,5 \mathrm{P}_{3}$ to sustain their activities ${ }^{27,33,34}$. These data suggest that the p53-PI3,4,5 $\mathrm{P}_{3}$ complex serves as a lipid reservoir that supports the Akt pathway activation in the nucleus. In support of this concept, $\mathrm{PI} 3,4,5 \mathrm{P}_{3}$ and Akt co-IP'ed with mutant $\mathrm{p} 53^{\mathrm{R} 280 \mathrm{~K}}$ and these interactions were enhanced by cisplatin (Fig. 5a,b), indicating p53, $\mathrm{Pl} 3,4,5 \mathrm{P}_{3}$ and Akt are associated in one complex. KD of p53, PIPKIa or IPMK decreased the interaction of mutant p53 with Akt measured by co-IP under basal or stressed conditions, while PTEN KD enhanced this interaction, underscoring the functional role of $\mathrm{PI}, 4,5 \mathrm{P}_{3}$ in the formation of the p53-Akt complex (Fig. 5c). Furthermore, KD of mutant p53 ${ }^{\mathrm{R} 280 \mathrm{~K}}$, PIPKIa, or IPMK reduced the nuclear pAkt ${ }^{\mathrm{S} 73}$ and $\mathrm{pFOXO3^{ \textrm {S } 2 5 3 }}$ content quantified by IF, whereas PTEN KD enhanced nuclear $\mathrm{pAkt}^{\mathrm{S43}}$ and $\mathrm{pFOXO3^{S253 }}$ levels (Fig. 5d,e and Extended Data Fig. 6a). Additionally, nuclear mutant $p 53^{\mathrm{R} 280 \mathrm{~K}}-\mathrm{pAkt}{ }^{\mathrm{S473}}$ and $\mathrm{p53}^{\mathrm{R} 280 \mathrm{~K}}-\mathrm{pFOXO3^{ \textrm {S } 2 5 3 }}$ complexes detected by PLA were diminished by KD of p53, PIPKIa, or IPMK, but enhanced by PTEN KD under basal and stressed conditions (Fig. 5f,g and Extended Data Fig. 6b). Notably, the cisplatin-induced nuclear Akt activation was blocked by the PIPKIa inhibitor ISA- 
2011B, but not by the class I PI3K inhibitors (Fig. 5h,i). These data indicate that PI3,4,5 $\mathrm{P}_{3}$ bound to p53 recruits and activates Akt in the nucleus and the activity of this nuclear p53phosphoinositide signalosome is dynamically regulated by phosphatidylinositol kinases and phosphatases and is separate from the canonical PI 3-kinase pathway.

\section{The p53-PI signalosome links the nuclear PI3K-Akt pathway to DNA-repair and cell survival}

$\mathrm{PDK} 14,5,33, \mathrm{mTORC2}{ }^{27}$, and $\mathrm{Akt}^{4}, 34,35$ require $\mathrm{PI} 3,4,5 \mathrm{P}_{3}$ binding to sustain their activation, and yet the nuclear Akt pathway functions in the non-membranous nucleoplasm. Nuclear pPDK1 ${ }^{\mathrm{S} 396}$ and $\mathrm{pFOXO3^{ \textrm {S } 2 5 3 }}$ localize to a speckle-like pattern of nuclear PIP-enriched structures ${ }^{36-38}$ (Fig. 2a and 3e). Indeed, double IF staining showed intense and stress-inducible colocalization of pPDK1 ${ }^{\mathrm{S} 396}$ and $\mathrm{pFOXO} 3^{\mathrm{S} 253}$ with nuclear PI4,5P2 (Fig. 6a,b and Extended Data Fig. 6c). The colocalization of the PDK1-Akt-FOXO complex with the nuclear PI reservoir localizes the nuclear p53-Akt pathway to these nonmembranous, Pl-enriched domains in the nucleoplasm.

Our observation that genotoxic stress promotes the assembly of the nuclear p53$\mathrm{PI} 3,4,5 \mathrm{P}_{3}$-Akt-FOXO complex suggested that this complex may play a role in DNA damage repair and/or apoptosis. Indeed, nuclear p53, Akt, FOXOs and phosphoinositides have all been implicated in the DNA damage response ${ }^{16,17,23,39}$ and we have previously localized the p53-PI4,5P2 complex to sites of DNA damage ${ }^{17}$. Using the histone H2A.X variant, $\gamma-\mathrm{H} 2 \mathrm{~A} . \mathrm{X}$, as a marker for sites of DNA double-strand breaks (DSBs) ${ }^{40}$, STED revealed a specific enrichment of $\mathrm{pAkt}^{\mathrm{S} 473}$ and its colocalization with both wild-type and mutant p53 at DNA damage sites (Fig. 6c,d and Extended Data Fig. 7a). KD of mutant 
p53, PIPKla or IPMK increased the cisplatin-induced $\gamma-\mathrm{H} 2 \mathrm{~A} . \mathrm{X}$ levels, while PTEN silencing diminished $\gamma-\mathrm{H} 2 \mathrm{~A} . \mathrm{X}$ levels (Fig. 6e,f). Moreover, KD of mutant p53, PIPKIa, or IPMK, sensitized cancer cells to cisplatin treatment and reduced cell invasion, whereas PTEN KD conferred resistance to genotoxic stress and enhanced cell invasion (Fig. 6gI). Collectively, these results support a pro-survival role of the nuclear p53-PI3,4,5 $\mathrm{P}_{3}$ complex that recruits and activates Akt at sites of DNA damage to attenuate genotoxic stress.

\section{The nuclear content of p53 results in Akt activation}

Wild-type p53 protein is normally expressed at low levels but is dramatically induced by stress, whereas mutant p53 is expressed at high basal levels due to enhanced protein stability ${ }^{15,16}$. There are also stochastic variations in the levels of both wild-type and mutant p53 in cells (Fig. 7a-c and Extended Data Fig. 7b-i). To assess the relationship between p53 and active nuclear Akt levels, we quantified the correlation between nuclear p53 and $\mathrm{pAkt}^{\mathrm{S} 473}$. Under basal and stressed conditions, there were strong correlations between nuclear p53 and pAkt ${ }^{S 473}$ levels with Pearson's $r$ greater than $0.7^{41}$. While the sporadic expression of wild-type p53 segregated the nuclear pAkt levels in an on/off mode, mutant p53 levels correlated with nuclear pAkt expression in a dose-dependent manner (Fig. 7ac). Moreover, levels of the nuclear Akt target pFOXO3 ${ }^{\mathrm{S} 253}$ also correlated with mutant p53 expression under basal and stressed conditions (Fig. 7d-g). In addition, the nuclear levels

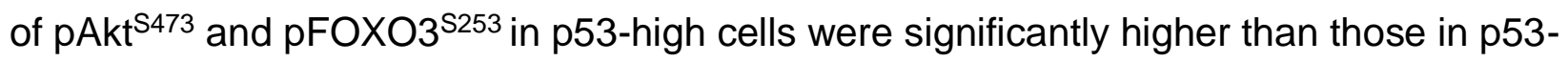
low cells. To refine this observation, we ectopically expressed Flag-tagged mutant p53 ${ }^{\mathrm{R} 175 \mathrm{H}}$ in $\mathrm{A} 549$ cells and observed that mutant p53 enhanced $\mathrm{pAkt}^{\mathrm{S473}}$ levels in the nucleus under basal conditions and more so after brief genotoxic stress. The nuclear 
content of $\mathrm{pAkt}^{\mathrm{S} 473}$ in mutant $\mathrm{p} 53^{\mathrm{R} 175 \mathrm{H}}$ expressing cells was significantly greater than those in mutant $\mathrm{p} 53^{\mathrm{R} 175 \mathrm{H}_{-}}$-negative cells (Fig. $\left.7 \mathrm{~h}-\mathrm{k}\right)$. These results demonstrate that $\mathrm{p} 53$ activates nuclear Akt in a dose-dependent fashion and this dose-dependence likely underlies the requirement of cellular stress to stabilize wild-type p53 to assemble the p53$\mathrm{PI}, 4,5 \mathrm{P}_{3}$-Akt complex and activate nuclear Akt, while hyperstabilized mutant p53 protein 15,16 constitutively activates this pathway with modest augmentation by stress.

\section{DISCUSSION}

Since the discovery of the nuclear generation of PIPs ${ }^{42}$ in regions spatially distinct from known membrane compartments ${ }^{38}$, key components of the canonical membranelocalized cytoplasmic PI3K-Akt pathway have been shown to be present in the nucleus ${ }^{36}$. Nuclear PI signaling enables the synthesis of PIPs and their dynamic interconversions through kinases and phosphatases with no detectable association with membranous structures, implying a distinct nuclear mechanism independent from the cytoplasmic pathway ${ }^{36,43}$. Accumulating evidence points to nuclear PDK1-mTORC2-Akt activation distinct from the classic membrane-localized cytosolic pathway8, 44-46. Notably, the nucleus contains all the machinery necessary for phosphorylating Akt to achieve full activation, including PIP kinases, PI3-kinases, PI4,5P2, PI3,4,5P 3 , PDK1, mTORC2, and Akt $^{8,}{ }^{36-38}$. In the canonical membrane-localized PI3K-Akt pathway, $\mathrm{PI} 3,4,5 \mathrm{P}_{3}$ recruits PDK1, mTORC2, and Akt to membranes via their PH domains ${ }^{27,33,34}$. Here, we report the discovery of a novel nuclear PI3K-Akt pathway independent of the membranelocalized pathway that is scaffolded on stress-activated wild-type and mutant p53 (Fig. 7I). This nuclear p53-PI signalosome dynamically binds to PIPKIa, IPMK and PTEN to enable stress-regulated modifications of PIPs associated with p53 with exquisite spatial 
and temporal specificity. The $\mathrm{PI}_{3}, 4,5 \mathrm{P}_{3}$ bound to p53 plays an analogous role in the nucleus by recruiting Akt, PDK1, and mTORC2 leading to activation of Akt in the complex.

The nuclear p53-PI3,4,5P3-Akt complex also recruits and phosphorylates FOXOs, known Akt substrates implicated in DNA damage-induced apoptosis ${ }^{23,39,47,48}$, and the resulting inactivating phosphorylation of FOXOs appears to mitigate DNA damage and apoptosis, underscoring the cytoprotective function of this complex. Indeed, the localization of the p53-PI3,4,5 $\mathrm{P}_{3}$-Akt complex at sites of DNA DSBs identified by $\gamma-\mathrm{H} 2 \mathrm{~A} . \mathrm{X}$ foci supports its role in the DNA damage response.

The discovery of a direct link between p53 and Akt and the dose-dependent induction of nuclear Akt activation by p53 point to a new function of p53. In the absence of stress, wild-type p53 is increased stochastically, activating nuclear Akt in an on/off mode, whereas mutant p53 activates nuclear Akt constitutively, reflecting the hyperstability of mutant relative to the wild-type $p 53^{15,16}$. The loss of transcriptional regulation by mutant p53 and its gain of Akt activation may be underlying mechanisms for its survival and proliferative roles in cancer. Consistent with this idea, knock-in of mutant p53 in mice leads to elevated Akt signaling and tumorigenesis ${ }^{49}$ and expression levels of $p 53$, a surrogate marker for p53 mutational status ${ }^{50,51}$, correlate with active Akt in human colorectal carcinomas 52 .

The nuclear p53-PI signalosome described here is not only spatially distinct from the membrane-localized PI3K-Akt pathway but also utilizes a different PI3K to generate $\mathrm{PI}, 4,5 \mathrm{P}_{3}$ bound $\mathrm{p53}$, the nuclear PI3K IPMK that interacts with $\mathrm{p} 53^{18}$. Importantly, the p53-PI signalosome and nuclear Akt activation is resistant to class I PI3K inhibitors 
including the a-specific inhibitor alpelisib ${ }^{53}$. As such, the discovery of the nuclear p53-PI signalosome has significant therapeutic implications for cancers driven by mutant p53. Finally, the discovery that PIPs tightly associate with key proteins such as p53 and the nuclear poly $(\mathrm{A})$ polymerase Star-PAP54 suggests that this may represent a "third messenger" system whereby second messengers in the canonical membrane-localized PI signaling pathway are linked to key regulatory proteins to confer new functional activities.

\section{ACKNOWLEDGMENTS}

We thank Drs. Anjon Audhya, Michael Sussman, and Wolfgang Peti for discussions and comments, and Lance Rodenkirch for technical support. This work was supported in part by a National Institutes of Health grant R35GM134955 (R.A.A.), Department of Defense Breast Cancer Research Program grants W81XWH-17-1-0258 (R.A.A.), W81XWH-17-10259 (V.L.C.) and W81XWH-21-1-0129 (V.L.C.), and a grant from the Breast Cancer Research Foundation (V.L.C.).

\section{AUTHOR CONTRIBUTIONS}

MC, SC, TW, CC, NT, VLC, and RAA designed the experiments. MC, SC, TW, CC, and NT performed the experiments. MC, VLC, and RAA wrote the manuscript.

\section{DECLARATION OF INTERESTS}

Authors declare that they have no competing interests.

\section{METHODS}




\section{Cell culture and constructs}

A549, BT-549, Cal33, HCT116, HS578T, MDA-MB-231, MDA-MB-468, SUM1315, HEK293FT, and MCF-10A cells were purchased from ATCC. GILM2 cells were described previously55. MCF10A cells were cultured as described ${ }^{56}$ and the other cells were maintained in DMEM (\#10-013-CV, Corning) supplemented with 10\% fetal bovine serum (\#SH30910.03, Hyclone) and 1\% penicillin/streptomycin (\#15140-122, Gibco). The cell lines used in this study were routinely tested for mycoplasma contamination, and mycoplasma negative cells were used. None of the cell lines used in this study is listed in the database of commonly misidentified cell lines maintained by ICLAC. The p53 constructs used for this work were described previously ${ }^{17}$. Constructs were transfected in mammalian cells by the lipid-based delivery system from Invitrogen (Lipofectamine ${ }^{\mathrm{TM}} 3000$, \#L3000015) according to the manufacturer's instructions. Typically, 2-5 $\mu \mathrm{g}$ of DNA and 6-10 $\mu \mathrm{l}$ of lipid were used for transfecting cells in 6-well plates. Cells that had at least $80 \%$ transfection efficiency were used for further analysis.

\section{Antibodies and reagents}

Monoclonal antibodies against p53 (clone DO-1, \#SC-126, Santa Cruz Biotechnology), p53 (clone 7F5, \#2527, Cell Signaling), Sin1 (clone D7G1A, \#12860, Cell Signaling), Akt (clone C67E7, \#4691, Cell Signaling), pAkt ${ }^{\$ 473}$ (clone 193H12, \#4058, Cell Signaling), pAkt ${ }^{\top 308}$ (clone D25E6, \#13038, Cell Signaling), PTEN (clone 17.A, \#MA5-12278, Invitrogen), FOXO1 (clone C29H4, \#2880, Cell Signaling), FOXO3 (clone D19A7, \#12829, Cell Signaling), GAPDH (clone 0411, \#sc-47724, Santa Cruz Biotechnology), and polyclonal antibodies against PIPKIa (PIP5K1A, \#9693, Cell Signaling), PDK1 (\#3062, 
Cell Signaling), pPDK1 ${ }^{\mathrm{S} 241}$ (\#ab131098, Abcam), pPDK15396(\#PA5-12888, Invitrogen), pFOXO1 ${ }^{\mathrm{T} 24} / \mathrm{FOXO}^{\mathrm{T32}}\left(\# 9464\right.$, Cell Signaling), pFOXO1 ${ }^{\mathrm{S319}}(\# 2486$, Cell Signaling),

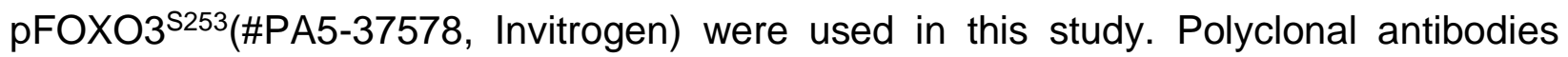
against PIPKI $\alpha \square$ and IPMK were produced as described previously ${ }^{56}$. For conventional immunostaining and PLA analysis of phosphoinositides, anti-PI4,5P2 (\#Z-P045) and $\mathrm{PI}_{3,4,5 \mathrm{P}_{3}}$ (\#Z-P345) antibodies were purchased from Echelon Biosciences. For immunoblotting analyses, antibodies were diluted at a 1:1000 ratio except for p53 (clone DO-1, 1:5000) and GAPDH (clone 0411, 1:5000). For immunoprecipitation, antibodyconjugated agarose was purchased from Santa Cruz Biotechnology, including agaroseconjugated antibodies against p53 (\#sc-126AC), PDK1 (\#sc-17765AC), Sin1 (\#sc393166AC), Akt (\#sc-5298AC), and Flag-tag (\#sc-166355AC). For immunostaining analyses and proximity ligation assay (PLA), antibodies were diluted at a 1:100 ratio. Nuclear envelope (Alexa Fluor®488 Lamin A/C, clone 4C11, \#8617, Cell Signaling, 1:200) and DNA damage site (Alexa Fluorß488- - -H2A.X, clone EP854(2)Y, \#ab195188, Abcam, 1:200) markers were used to examine subnuclear regions. For recombinant protein production, the DNA constructs for His-tagged p53, PIPKIa, IPMK, and PTEN were purchased from Genscript and the recombinant proteins were purified as previously described ${ }^{17}$. Recombinant Akt1 (\#ab79792) and PDK1 (also known as PDPK1, \#ab60834) were purchased from Abcam, and the recombinant Sin1 (also known as MAPKAP1, \#TP311745) was purchased from Origene. For the knockdown experiments, pooledsiRNAs targeting the 3'UTR of IPMK (sense 5'-CCAAGAGAGCUGGAAUUCUAUAAUA3' and antisense 5'-UAUUAUAGAAUUCCAGCUCUCUUGG-3'; sense 5'CAAAGGACAACUGUCAGACACAGAA-3' and antisense UUCUGUGUCUGACAGUUGUCCUUUG-3') were purchased from Thermo Fisher 
Scientific. The ON-TARGETplus siRNA pool against human p53, PIPKIa, and PTEN was purchased from Dharmacon. Non-targeting siRNA (Dharmacon) was used as a control. siRNAs were delivered to cells by RNAiMAX reagent (\#13778150, Invitrogen), and knockdown efficiency was determined by immunoblotting. Knockdown efficiency greater than $80 \%$ was required to observe phenotypic changes in the study. The PIPKIa inhibitor ISA-2011B (\#HY-16937) was purchased from MedChemExpress. Cisplatin (\#S1166) and class I PI3K inhibitors alpelisib (BYL719, \#S2814) and buparlisib (BKM120, \#S2247) were purchased from Sellekchem.

\section{Immunoprecipitation and immunoblotting}

Cells were removed from the medium after the indicated treatment, washed once with ice-cold PBS, and lysed in an ice-cold RIPA lysis buffer system (\#sc-24948, Santa Cruz Biotechnology) with $1 \mathrm{mM} \mathrm{Na}_{3} \mathrm{VO}_{4}, 5 \mathrm{mM} \mathrm{NaF}$, and 1x protease inhibitor cocktail (\#11836153001, Roche). The cell lysates were then sonicated at 15\% amplitude for $15 \mathrm{s.}$ After sonication, the cell lysates were incubated at $4^{\circ} \mathrm{C}$ with continuous rotation for $1 \mathrm{~h}$ and subsequently centrifuged at maximum speed for $10 \mathrm{~min}$ to collect the supernatant. The protein concentration in the supernatant was measured by the Bradford protein assay (\#5000201, BIO-RAD) according to the manufacturer's instructions. Equal amounts of protein were used for further analysis. All antibodies were diluted at a 1:1000 ratio for immunoblotting. For immunoprecipitation, $0.5-1 \mathrm{mg}$ of protein was incubated with $20 \mu \mathrm{l}$ of antibody-conjugated agarose (Santa Cruz Biotechnology) at $4^{\circ} \mathrm{C}$ for $24 \mathrm{~h}$. After washing five times with lysis buffer, the protein complex was eluted with SDS sample buffer. For immunoblotting, 5-20 $\mathrm{\mu g}$ of protein were loaded. For immunoblotting of immunoprecipitated complexes, horseradish peroxidase (HRP)-conjugated antibodies 
were used to avoid non-specific detection of immunoglobulin in the immunoprecipitated samples. HRP-conjugated p53 (\#sc-126HRP), PDK1 ((\#sc-17765HRP), and Sin1 (\#sc393166HRP) antibodies were purchased from Santa Cruz Biotechnology. Immunoblots were developed by Odyssey Imaging System (LI-COR Biosciences) and the intensity of protein bands was quantified using ImageJ. The unsaturated exposure of immunoblot images was used for quantification with the appropriate loading controls as standards. Statistical analysis of the data was performed with Microsoft Excel, using data from at least three independent experiments.

\section{Fluorescent IP-WB}

Cells were lysed in a RIPA lysis buffer system after the indicated treatment and quantified for protein concentration as described above. For endogenous p53 or FLAG-tagged p53 immunoprecipitation, 0.5-1 mg of cell lysates were incubated with $20 \mu$ lanti-p53 (\#sc-126 AC, Santa Cruz Biotechnology) or anti-FLAG (\#sc-166355AC, Santa Cruz Biotechnology) mouse monoclonal IgG antibody-conjugated agarose at $4^{\circ} \mathrm{C}$ for $24 \mathrm{~h}$. Normal immunoglobulin (lgG)-conjugated agarose was used as a negative control (\#sc-2343, Santa Cruz Biotechnology). After washing 5 times with PBST (PBS with 0.1\% Tween 20), the protein complex was eluted with SDS sample buffer. The sample was then boiled at $95^{\circ} \mathrm{C}$ for $10 \mathrm{~min}$. For immunoblotting, 5-20 $\mu \mathrm{g}$ of protein were loaded. The protein complexes associated with p53 were resolved by SDS-PAGE and transferred onto a PVDF membrane (\#IPVH00010, Millipore). The membrane was blocked with 3\% BSA in PBS for $1 \mathrm{~h}$ at room temperature. For double fluorescent IP-WB detecting p53-

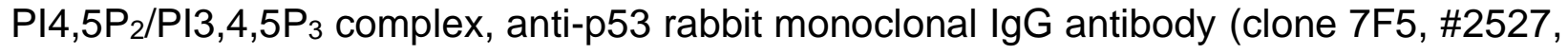
Cell Signaling) at 1:2000 dilution and anti-PI4,5P2 mouse monoclonal lgM antibody (\#Z- 
P045, Echelon Biosciences) or $\mathrm{Pl3}, 4,5 \mathrm{P}_{3}$ mouse monoclonal IgM antibody (\#Z-P345, Echelon Biosciences) at 1:2000 dilution were mixed together in blocking buffer with $0.02 \%$ Sodium Azide and incubated with the membrane at $4^{\circ} \mathrm{C}$ overnight. The next day, the membrane was washed three times with PBST for 10 min each time. For the secondary antibody incubation, goat anti-rabbit IgG antibody conjugated with IRDye 800CW fluorophore (\#926-32211, LI-COR) detectable on the $800 \mathrm{~nm}$ wavelength channel of the Odyssey Fc Imaging System (LI-COR Biosciences) and goat anti-mouse IgM antibody conjugated with IRDye 680RD fluorophore (\#926-68180, LI-COR) detectable on the 700 $\mathrm{nm}$ wavelength channel at 1:10000 dilution were mixed together in blocking buffer with $0.01 \%$ SDS and $0.1 \%$ Tween 20 and incubated with the membrane at room temperature for $2 \mathrm{~h}$. The membrane was then washed three times with PBST for 10 min each time. The images were subsequently acquired using the 700 and $800 \mathrm{~nm}$ wavelength channels simultaneously on the Odyssey Fc Imaging System (LI-COR Biosciences). The p53associated $\mathrm{P} 14,5 \mathrm{P}_{2} / \mathrm{PI}_{3}, 4,5 \mathrm{P}_{3}$ complex was visualized by overlapping the 700 and $800 \mathrm{~nm}$ channels. For triple fluorescent IP-WB, Alexa fluor 594 Dye (detectable on the $600 \mathrm{~nm}$ channel), IRDye 680RD (detectable on the $700 \mathrm{~nm}$ channel), and IRDye $800 \mathrm{CW}$ (detectable on the $800 \mathrm{~nm}$ channel) conjugated antibodies were used together to visualize the complex by overlapping the 600,700 , and $800 \mathrm{~nm}$ channels. Statistical analysis of the data was performed with Microsoft Excel, using data from at least three independent experiments.

\section{In vitro binding assay}

His-tagged p53 protein was expressed in BL-21(DE3) E. coli (\#EC0114, Thermo Fisher), lysed with $1 \%$ Brij58, sonicated, and purified with Ni-NTA-agarose (\#166038887, Qiagen) 
as previously described ${ }^{17}$. The eluates were buffer-exchanged into PBS using a dialysis cassette (\#66380, Thermo Fisher Scientific), flash-frozen, and stored at $-80{ }^{\circ} \mathrm{C}$. Recombinant Akt1 protein was purchased from Abcam (\#ab79792). The binding assay was performed in PBST by incubating a constant amount of His-tagged p53 with an increasing amount of Akt1 in the presence of $20 \mu \mathrm{l}$ anti-p53 antibody-conjugated agarose (\#sc-126AC, Santa Cruz). After incubating overnight at $4^{\circ} \mathrm{C}$, unbound proteins were removed by washing three times with PBST, and the protein complex was analyzed by immunoblotting.

\section{Microscale Thermophoresis (MST) Assay}

The MST assay was used to measure the binding affinity of purified recombinant proteins in vitro as described previously ${ }^{57}$. The target protein was fluorescently labeled by Monolith Protein Labeling Kit RED-NHS 2nd Generation (\#MO-L011, Nano Temper) following the manufacturer's instruction. A sequential titration of unlabeled ligand proteins, PI-PolyPIPosomes, or PI-micelles was made in a Tris-based MST buffer containing 50 $\mathrm{mM}$ Tris- $\mathrm{HCl}, \mathrm{pH} 8.0,50 \mathrm{mM} \mathrm{NaCl}, 80 \mathrm{mM} \mathrm{KCl}$, and $0.05 \%$ Tween-20 and mixed with an equal volume of fluorescently labeled target protein prepared at $10 \mathrm{nM}$ concentration in the same MST buffer, making the final target protein at a constant concentration of $5 \mathrm{nM}$ and the ligand protein or lipid as the gradient. The PI-PolyPIPosomes for MST were purchased from Echelon Biosciences, including PI PolyPIPosomes (\#Y-P000), PI4,5P2 PolyPIPosomes (\#Y-P045), and PI3,4,5P3 PolyPIPosomes (\#Y-P039). The synthetic Pls for MST were also purchased from Echelon Biosciences, including PI diC16 (\#P-0016), $\mathrm{PI}$ 4,5P 2 diC16 (\#P-4516), and PI3,4,5P 3 diC16 (\#P-3916), which were dissolved in the MST buffer with 5 min sonication to prepare the PI-micelles. The target-ligand mixtures 
were loaded into Monolith NT.115 Series capillaries (\#MO-K022, Nano Temper) and the MST traces were measured by Monolith NT.115 pico, and the binding affinity was autogenerated by MO. Control v1.6 software.

\section{Immunofluorescence (IF), Confocal and STED Microscopy}

For immunofluorescence studies, cells were grown on coverslips coated with $0.2 \%$ gelatin (\#G9391, Millipore Sigma). Cells were fixed with 4\% paraformaldehyde (PFA) (\#sc-281692, Santa Cruz Biotechnology) for $20 \mathrm{~min}$ at room temperature followed by washing three times with PBS. Next, the cells were permeabilized with $0.3 \%$ Triton-X100 for 10 min and rewashed three times with PBS. The cells were then blocked with $3 \%$ BSA in PBS for one hour at room temperature. After blocking, cells were incubated with a primary antibody overnight at $4^{\circ} \mathrm{C}$. The cells were then washed three times with PBS and incubated with fluorescent-conjugated secondary antibodies (Molecular Probes) for 1 hour at room temperature. For STED super-resolution microscopy, secondary antibodies conjugated with Abberior® STAR RED/580 dyes were used at 1:200 dilution (\#41699 and \#52405, Millipore Sigma). After secondary antibody incubation, the cells were washed three times with PBS and nuclei counterstained with $1 \mu \mathrm{g} / \mathrm{ml}$ 4',6-diamidino-2phenylindole (DAPI) (\#D3571, Invitrogen) in PBS for $30 \mathrm{~min}$ at room temperature. The cells were subsequently washed three times with PBS and mounted in Prolong ${ }^{\mathrm{TM}}$ Glass Antifade Mountant media (\#P36984, Thermo Fisher Scientific). The images were taken by Leica SP8 3xSTED Super-Resolution Microscope, which is both a point scanning confocal and 3xSTED super-resolution microscope. The Leica SP8 3xSTED microscope was controlled by LASX software (Leica Microsystems). All images were acquired using the 100X objective lens (N.A. 1.4 oil). The z-stack images were taken with each frame 
over a $0.2 \mu \mathrm{m}$ thickness. For quantification, the mean fluorescent intensity of channels in each cell was measured by LASX. The colocalization of double staining channels was quantified by LASX using Pearson's correlation coefficient (Pearson's r), ranging between 1 and -1 . A value of 1 represents perfect correlation, 0 means no correlation, and -1 means perfect negative correlation ${ }^{58}$. Pearson's $r$ greater than 0.7 suggests a strong correlation $^{41}$. The quantitative graph was generated by GraphPad Prism. The images were processed using ImageJ.

\section{Proximity Ligation Assay (PLA)}

PLA was utilized to detect in situ protein-protein/PI interaction as previously described ${ }^{17}$, 58, 59. After fixation and permeabilization, cells were blocked before incubation with primary antibodies as in routine IF staining. The cells were then processed for PLA (\#DUO92101, Millipore Sigma) according to the manufacturer's instruction and previously published $^{58,59}$. The slides post-PLA were further processed for immunofluorescent staining against the nuclear membrane marker (Lamin A/C, \#8617, Cell Signaling). The slides were mounted with Duolink® In Situ Mounting Medium with DAPI (\#DUO82040, Millipore Sigma). The Leica SP8 confocal microscope detected PLA signals as discrete punctate foci and provided the intracellular localization of the complex. ImageJ was used to quantify the nuclear PLA foci.

\section{MTT cell viability assay}

In 96-well plates, $5 \times 10^{4}$ cells/well were transfected with control siRNAs or siRNAs targeting p53, PIPKIa, IPMK, and PTEN for $48 \mathrm{~h}$. The cells were then treated with control vehicle or $30 \mu \mathrm{M}$ cisplatin for $20 \mathrm{~h}$. Next, the cells were incubated with $100 \mu \mathrm{l}$ of fresh medium plus $10 \mu$ l of the $12 \mathrm{mM}$ MTT stock solution from the Vybrant ${ }^{\circ}$ MTT cell 
proliferation assay kit (\#V13154, Thermo Fisher Scientific) in the presence of the control vehicle or $30 \mu \mathrm{M}$ cisplatin. After incubation for 4 hours at $37^{\circ} \mathrm{C}$, all but $25 \mu \mathrm{l}$ of the medium was removed from each well and $50 \mu$ of DMSO was added. The mixture was incubated at $37^{\circ} \mathrm{C}$ for $10 \mathrm{~min}$, and the absorbance was read at $540 \mathrm{~nm}$ using a Synergy HTX MultiMode Microplate reader (BioTek Instruments, Inc.).

\section{Cell death detection ELISA}

In 96-well plates, $5 \times 10^{4}$ cells/well were transfected with control siRNAs or siRNAs targeting p53, PIPKIa, IPMK, and PTEN for $48 \mathrm{~h}$. The cells were then treated with control vehicle or $30 \mu \mathrm{M}$ cisplatin for $24 \mathrm{~h}$. Next, the cells were lysed and processed for cell death detection ELISA assay by following the manufacturer's instruction (\#11774425001, Millipore Sigma). At the end of the assay, the absorbance was read at $405 \mathrm{~nm}$ using a Synergy HTX Multi-Mode Microplate reader.

\section{Transwell Invasion Assay}

The bottom polycarbonate filter surface of a $6.5 \mathrm{~mm}$ diameter insert with $8 \mu \mathrm{m}$ pores in a 24-well plate (\#3422, Corning) was coated with $10 \mu \mathrm{g} / \mathrm{ml}$ of Laminin (\#CC095, Millipore) diluted in PBS for $3 \mathrm{~h}$ at $37^{\circ} \mathrm{C}$. MDA-MB-231 cells were transiently transfected with control siRNAs or siRNAs targeting p53, PIPKIa, IPMK, and PTEN, then serum-starved for $24 \mathrm{~h}$. Next, $5 \times 10^{4}$ transfected cells were suspended in $200 \mu$ serum-free medium containing 0.5\% BSA and then were plated in the upper insert chamber in $500 \mu \mathrm{l}$ serum-free medium with $0.5 \%$ BSA. $10 \mathrm{ng} / \mathrm{ml}$ EGF was added to the lower chamber. Cells were allowed to invade for $16 \mathrm{~h}$ at $37^{\circ} \mathrm{C}$. Cells on the bottom of the filter were then fixed with $4 \%$ PFA and stained with $0.1 \%$ Crystal Violet. The stained cells were imaged using an EVOS M5000 
microscope (Thermo Fisher Scientific). At the end of the assay, the dye was extracted from the cells and quantified by measuring the optical density at $570 \mathrm{~nm}$ using a Synergy HTX Multi-Mode Microplate reader.

\section{Statistics and Reproducibility}

Two-tailed unpaired $t$-tests were used for pair-wise significance unless otherwise indicated. We note that no power calculations were used. Sample sizes were determined based on previously published experiments where significant differences were observed 17. Each experiment was repeated at least three times independently, and the number of repeats is defined in each figure legend. We used at least three independent experiments or biologically independent samples for statistical analysis.

\section{Resource and Data Availability}

All data supporting the findings of this study are available from the corresponding authors on reasonable request.

\section{FIGURE LEGEND}

Figure 1. p53 interacts with nuclear Akt and regulates its activation

a-c, Confocal images of IF staining against pAkt ${ }^{\top 308} / \mathrm{pAkt}^{\mathrm{S} 473}$ and $\mathrm{p53}$ in MDA-MB-231 cells treated with control vehicle or $30 \mu \mathrm{M}$ cisplatin for $24 \mathrm{~h}$. The nuclear levels of


quantified. $\mathrm{N}=30$ cells from representative experiments of three repeats.

d-f, STED super-resolution images of IF staining against pAkt ${ }^{\mathrm{S} 473}$ and $\mathrm{p53}$ in MDA-MB231 cells treated with control vehicle or $30 \mu \mathrm{M}$ cisplatin for $24 \mathrm{~h}$. The nuclear levels of 
pAkt $^{\mathrm{S473}}$ and p53 (e) and their colocalization (f) were quantified. $\mathrm{N}=30$ cells from representative experiments of three repeats.

g, Quantification of nuclear PLA complexes of p53-Akt/pAkt ${ }^{T 308 / p A k t}{ }^{S 473}$ in $A 549$ and MDA-MB-231 cells treated with control vehicle or $30 \mu \mathrm{M}$ cisplatin for $24 \mathrm{~h} . \mathrm{N}=30$ cells from representative experiments of three repeats. See PLA images in Extended Data Fig. 2a. h, PLA of p53-pAkt ${ }^{\top 308} / p_{A k t}{ }^{473}$ overlaid with nuclear envelope marker Lamin A/C in MDAMB-231 cells treated with control vehicle or $30 \mu \mathrm{M}$ cisplatin for $24 \mathrm{~h}$.

i-k, Immunoprecipitation (IP) of endogenous p53 and Akt from MDA-MB-231 and A549 cells treated with control vehicle or $30 \mu \mathrm{M}$ cisplatin for $24 \mathrm{~h}$. The Akt IP-ed by mutant p53 (i), mutant p53 IP-ed by Akt (j), and wild-type p53 IP-ed by Akt (k) were analyzed by WB. $\mathrm{N}=3$.

I, IP of p53 and Akt from MDA-MB-231 cells treated with $100 \mu \mathrm{M}$ tert-butylhydroquinone (tBHQ), $100 \mu \mathrm{M}$ hydroxyurea, $100 \mu \mathrm{M}$ etoposide, $30 \mu \mathrm{M}$ cisplatin, or control vehicle for 24 h. Representative data of three independent experiments are shown.

m, In vitro binding of recombinant p53 with Akt1. A constant amount of p53 immobilized on anti-p53 agarose was incubated with the indicated increasing amounts of Akt1. p53 was IP'ed and p53-bound Akt1 was analyzed by WB. Representative data of three independent experiments are shown.

n-o, IF staining of $\mathrm{p53}$ and $\mathrm{pAkt} \mathrm{t}^{\mathrm{S} 73}$ in MDA-MB-231 cells $48 \mathrm{~h}$ after transient transfection with control siRNAs or siRNAs against p53. The nuclear p53 and pAkt ${ }^{\mathrm{S473}}$ levels were quantified (o). $\mathrm{N}=30$ cells from representative experiments of three repeats.

For all panels, data are represented as mean $\pm S D, p<0.01={ }^{* *}$, t test. Scale bar: $5 \mu$ m.

Figure 2. p53 recruits upstream Akt-activating kinases in the nucleus 
a-c, IF staining against pPDK1 ${ }^{\text {s241/pPDK1 }}{ }^{\mathrm{S} 396}$ and $\mathrm{p53}$ in MDA-MB-231 cells treated with

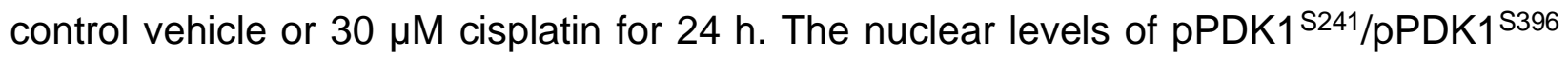
and p53 (b) and their colocalization (c) were quantified. $\mathrm{N}=30$ cells from representative experiments of three repeats.

d-e, PLA of p53-PDK1/Sin1 in A549 and MDA-MB-231 treated with control vehicle or 30 $\mu \mathrm{M}$ cisplatin for $24 \mathrm{~h}$. The nuclear PLA foci of $\mathrm{p53-PDK1/pPDK1}{ }^{\mathrm{s} 241 / p P D K} 1^{\mathrm{s} 396} / \mathrm{Sin} 1$ were

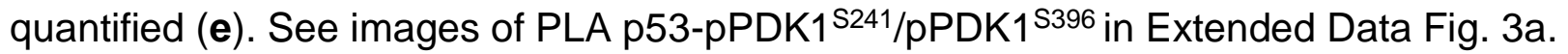

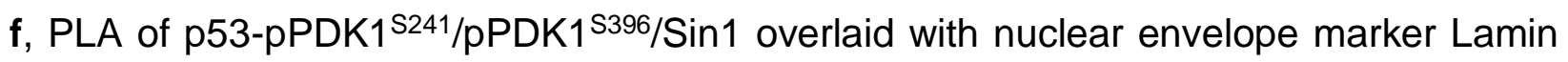
$\mathrm{A} / \mathrm{C}$ in MDA-MB-231 cells treated with control vehicle or $30 \mu \mathrm{M}$ cisplatin for $24 \mathrm{~h}$.

g-j, IP of endogenous p53 and PDK1/Sin1 from MDA-MB-231 and A549 cells treated with control vehicle or $30 \mu \mathrm{M}$ cisplatin for $24 \mathrm{~h}$. The mutant and wild-type p53 IP-ed by PDK1 $(\mathbf{g}, \mathbf{h})$, and the mutant and wild-type p53 IP-ed by $\operatorname{Sin} 1(\mathbf{i}, \mathbf{j})$ were analyzed by WB. N=3. See also Extended Data Fig. 2d.

k, Schematic diagram summarizes the nuclear stress-induced p53 complex that activates Akt.

For all panels, data are represented as mean $\pm S D, p<0.01={ }^{* *}$, t test. Scale bar: $5 \mu$ m.

\section{Figure 3. The nuclear p53-Akt complex targets FOXOs}

a, Domain map of FOXO family members and their phosphorylation sites by Akt.

b-d, IP analysis of total and phosphorylated forms of FOXOs in association with Akt and p53 in MDA-MB-231 cells treated with control vehicle or $30 \mu \mathrm{M}$ cisplatin for $24 \mathrm{~h}$. The FOXOs in association with Akt (c) and p53 (d) were quantified. $\mathrm{N}=3$.

e-f, IF staining of $\mathrm{p} 53$ and pFOXO3 ${ }^{\mathrm{S} 253}$ in A549 and MDA-MB-231 cells treated with control vehicle or $30 \mu \mathrm{M}$ cisplatin for $24 \mathrm{~h}$. The nuclear colocalization of p53 and 
pFOXO3 ${ }^{\mathrm{S} 253}$ was quantified (f). $\mathrm{N}=30$ cells from representative experiments of three repeats.

g, Quantification of nuclear PLA complexes of p53 with FOXOs in A549 and MDA-MB231 treated with control vehicle or $30 \mu \mathrm{M}$ cisplatin for $24 \mathrm{~h} . \mathrm{N}=30$ cells from representative experiments of three repeats. See PLA images in Extended Data Fig. 3b.

h, PLA of p53-FOXOs overlaid with nuclear envelope marker Lamin A/C in MDA-MB-231 cells treated with control vehicle or $30 \mu \mathrm{M}$ cisplatin for $24 \mathrm{~h}$.

i-j, IF staining of p53 and pFOXO3 $3^{S 253}$ in MDA-MB-231 cells $48 \mathrm{~h}$ after transient transfection with control siRNAs or siRNAs against p53. The nuclear p53 and pFOXO3 ${ }^{\mathrm{S} 253}$ levels were quantified (j). $\mathrm{N}=30$ cells from representative experiments of three repeats.

For all panels, data are represented as mean $\pm S D, p<0.01={ }^{* *}$, t test. Scale bar: $5 \mu \mathrm{m}$.

Figure 4. $\mathrm{p} 53$ binds $\mathrm{PI}, 4,5 \mathrm{P}_{3}$ and IPMK and $\mathrm{PTEN}$ regulate the interconversion of nuclear p53-PI complexes

a, Fluorescent IP-WB detects on-site $\mathrm{PI}, 5 \mathrm{P}_{2}$ and $\mathrm{PI}, 4,5 \mathrm{P}_{3}$ association with epitopetagged p53 downstream of PIPKIa. FLAG-tagged mutant $(\mathrm{R} 175 \mathrm{H})$ or wild-type p53 were transient-transfected into HEK293FT cells for $24 \mathrm{~h}$. Then the cells were treated with 50 $\mu \mathrm{M}$ PIPKla inhibitor ISA-2011B (ISA) for $24 \mathrm{~h}$. The ectopically-expressed p53 was IP-ed with FLAG antibody and analyzed by WB using fluorescent antibodies detecting $\mathrm{PI}_{4,5 \mathrm{P}_{2} \text {, }}$ $\mathrm{PI}, 4,5 \mathrm{P}_{3}$, and p53 simultaneously. $\mathrm{N}=3$.

b, Fluorescent IP-WB detects on-site $\mathrm{PI}, 5 \mathrm{P}_{2}$ and $\mathrm{PI}, 4,5 \mathrm{P}_{3}$ association with endogenous mutant p53 and stress-induced wild-type p53 in a panel of cancer cells. A549 cells expressing wild-type p53 were treated with $30 \mu \mathrm{M}$ cisplatin or control vehicle for $24 \mathrm{~h}$ 
before being processed for IP against p53. BT-549, GILM2, HS578T, MDA-MB-231, and MDA-MB-468 cells expressing mutant p53 were directly processed for IP against mutant p53. The on-site $\mathrm{Pl} 4,5 \mathrm{P}_{2}$ and $\mathrm{PI}, 4,5 \mathrm{P}_{3}$ association with p53 was analyzed simultaneously by WB using fluorescent antibodies. $\mathrm{N}=3$.

c, Fluorescent IP-WB detects stress-induced $\mathrm{PI}, 4,5 \mathrm{P}_{3}$ association with endogenous mutant p53 downstream of PIPKla but independent from class I PI3Ks. MDA-MB-231 cells were treated with control vehicle or $30 \mu \mathrm{M}$ cisplatin with or without the presence of the a-specific PI3K inhibitor alpelisib $(10 \mu \mathrm{M})$, the pan-PI3K inhibitor buparlisib $(2 \mu \mathrm{M})$, or the PIPKIa inhibitor ISA-2011B $(50 \mu \mathrm{M})$ for $24 \mathrm{~h}$. Then the cells were processed for IP against p53 and analyzed by WB using fluorescent antibodies detecting $\mathrm{PI}, 4,5 \mathrm{P}_{3}$ and p53 simultaneously. $\mathrm{N}=3$.

d-e, PLA of p53-PI4,5P2/PI3,4,5 $\mathrm{P}_{3} / \mathrm{IPMK} / \mathrm{PTEN}$ overlaid with nuclear envelope marker Lamin A/C in MDA-MB-231 cells treated with control vehicle or $30 \mu \mathrm{M}$ cisplatin for $24 \mathrm{~h}$. The nuclear PLA foci were quantified (e). $\mathrm{N}=30$ cells from representative experiments of three repeats.

f, IP of IPMK with wild-type and mutant p53 from HCT116 and Cal33 cells respectively treated with $30 \mu \mathrm{M}$ cisplatin or control vehicle for $24 \mathrm{~h}$. Representative data of three independent experiments are shown.

g, IP of PTEN with wild-type and mutant p53 from A549 and MDA-MB-231 cells respectively treated with $30 \mu \mathrm{M}$ cisplatin or control vehicle for $24 \mathrm{~h}$. Representative data of three independent experiments are shown.

h-i, Quantification of the nuclear PLA foci of p53-PI4,5P $/ \mathrm{PI}_{3}, 4,5 \mathrm{P}_{3}$ in MDA-MB-231 cells $48 \mathrm{~h}$ after transient transfection with control siRNAs or siRNAs against PIPKIa, IPMK, and 
PTEN. $\mathrm{N}=30$ cells from representative experiments of three repeats. See PLA images in Extended Data Fig. 5k and knockdown validation by WB in Extended Data Fig. 5I.

j, Schematic illustration of p53 in a complex with $\mathrm{PI}, 5 \mathrm{P}_{2}$ and $\mathrm{PI}, 4,5 \mathrm{P}_{3}$ downstream of PIPKIa and their interconversion by IPMK and PTEN.

For all panels, data are represented as mean $\pm S D, p<0.01={ }^{* *}$, t test. Scale bar: $5 \mu \mathrm{m}$.

\section{Figure 5. p53-PI3,4,5 $\mathrm{P}_{3}$ recruits and activates the nuclear Akt pathway}

a-b, Triple fluorescent IP-WB detects stress-induced Akt association with the p53$\mathrm{PI}, 4,5 \mathrm{P}_{3}$ complex. MDA-MB-231 cells were treated with $30 \mu \mathrm{M}$ cisplatin or control vehicle for 24 before being processed for IP against p53 and analyzed by WB using fluorescent antibodies detecting Akt, $\mathrm{Pl3}, 4,5 \mathrm{P}_{3}$, and p53 simultaneously. The p53 associated $\mathrm{PI}, 4,5 \mathrm{P}_{3}$ and Akt were quantified (b). $\mathrm{N}=3$.

c, MDA-MB-231 cells were transfected with control siRNAs or siRNAs against p53, PIPKIa, IPMK, and PTEN. $24 \mathrm{~h}$ later, cells were treated with $30 \mu \mathrm{M}$ cisplatin or control vehicle for $24 \mathrm{~h}$ before being processed for IP against Akt. The Akt-associated p53 and the input of whole cell lysates were analyzed by WB. Representative images of three independent experiments are shown.

d-e, IF staining of p53 and pAkt ${ }^{S 473}$ in MDA-MB-231 cells $48 \mathrm{~h}$ after transient transfection with control siRNAs or siRNAs against p53, PIPKIa, IPMK, and PTEN. The nuclear pAkt $^{\mathrm{S} 473}$ levels were quantified (e). $\mathrm{N}=30$ cells from representative experiments of three repeats.

$\mathbf{f - g}, \mathrm{MDA}-\mathrm{MB}-231$ cells were transfected with control siRNAs or siRNAs against p53, PIPKIa, IPMK, and PTEN. $24 \mathrm{~h}$ later, cells were treated with $30 \mu \mathrm{M}$ cisplatin or control 
vehicle for $24 \mathrm{~h}$ before processing for PLA between p53 and pAkt ${ }^{S 473}$. The nuclear PLA foci were quantified $(\mathbf{g})$. N=30 cells from representative experiments of three repeats.

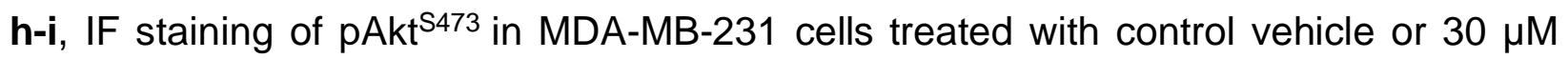
cisplatin for $24 \mathrm{~h}$ with or without the presence of the PI3Ka inhibitor alpelisib $(10 \mu \mathrm{M})$, the pan-PI3K inhibitor buparlisib $(2 \mu \mathrm{M})$, or the PIPKIa inhibitor ISA-2011B (50 $\mu \mathrm{M})$. The nuclear pAkt ${ }^{\mathrm{S} 43}$ levels were quantified (i). $\mathrm{N}=30$ cells from representative experiments of three repeats.

For all panels, data are represented as mean $\pm S D, p<0.01={ }^{* *}$, t test. Scale bar: $5 \mu \mathrm{m}$.

Figure 6. The p53-PI signalosome links the nuclear PI3K-Akt pathway to DNArepair and cell survival

a-b, MDA-MB-231 cells were treated with $30 \mu \mathrm{M}$ cisplatin or control vehicle for $24 \mathrm{~h}$ before being processed for IF staining against $\mathrm{PI} 4,5 \mathrm{P}_{2}$ and $\mathrm{pPDK} 1^{\mathrm{s} 396} / \mathrm{pFOXO} 3^{\mathrm{S} 253}$. The nuclear colocalization of $\mathrm{PI} 4,5 \mathrm{P}_{2}$ and $\mathrm{pPDK} 1^{\mathrm{S} 396} / \mathrm{pFOXO3^{ \textrm {S } 2 5 3 }}$ was quantified (B). $\mathrm{N}=30$ cells from representative experiments of three repeats. Scale bar: $5 \mu \mathrm{m}$. See Extended Data Fig. 6c for extended images.

c-d, STED super-resolution images of IF staining against p53, $\mathrm{pAkt}^{\mathrm{S473}}$, and the DNA DSB marker $\mathrm{X}-\mathrm{H} 2 \mathrm{~A} . \mathrm{X}$ in MDA-MB-231 or A549 cells treated with $30 \mu \mathrm{M}$ cisplatin or control vehicle for $24 \mathrm{~h}$. The nuclear colocalization of $\mathrm{p} 53$, $\mathrm{pAkt}^{\mathrm{S473}}$, and $\mathrm{X}-\mathrm{H} 2 \mathrm{~A} . \mathrm{X}$ was quantified (d). $\mathrm{N}=30$ cells from representative experiments of three repeats. Scale bar: $5 \mu \mathrm{m}$. See Extended Data Fig. 7a for extended images.

e-f, MDA-MB-231 cells were transfected with control siRNAs or siRNAs against p53, PIPKIa, IPMK, and PTEN. $24 \mathrm{~h}$ later, cells were treated with $30 \mu \mathrm{M}$ cisplatin or control vehicle for $24 \mathrm{~h}$ before being processed for IF staining against $\mathrm{X}-\mathrm{H} 2 \mathrm{~A}$.X. The nuclear level 
of $\mathrm{X}-\mathrm{H} 2 \mathrm{~A} . \mathrm{X}$ was quantified (f). $\mathrm{N}=30$ cells from representative experiments of three repeats. Scale bar: $5 \mu \mathrm{m}$.

g-i, MDA-MB-231, HS578T, MDA-MB-468 cells were transfected with control siRNAs or siRNAs against p53, PIPKIa, IPMK, and PTEN. 24 h later, cells were treated with $30 \mu \mathrm{M}$ cisplatin or control vehicle for $24 \mathrm{~h}$ before being processed for MTT cell viability assay. $\mathrm{N}=9$ from three independent experiments, each in triplicate.

j, MDA-MB-231 cells were transfected with control siRNAs or siRNAs against p53, PIPKIa, IPMK, and PTEN. $24 \mathrm{~h}$ later, cells were treated with $30 \mu \mathrm{M}$ cisplatin or control vehicle for $24 \mathrm{~h}$ before being processed for cell death detection ELISA. $\mathrm{N}=9$ from three independent experiments, each in triplicate.

k-I, MDA-MB-231 cells were transfected with control siRNAs or siRNAs against p53, PIPKIa, IPMK, and PTEN. $24 \mathrm{~h}$ later, cells were serum-starved for $24 \mathrm{~h}$ and then scored for invasion through Laminin-coated transwell inserts with $8 \mu \mathrm{m}$ pores using a $10 \mathrm{ng} / \mathrm{ml}$ EGF chemoattractant for $16 \mathrm{~h}$. The invading cells at the insert bottom were stained with crystal violet, imaged, and quantified based on the extracted dye using a plate reader. $\mathrm{N}=4$. Scale bar: $100 \mu \mathrm{m}$.

For all panels, data are represented as mean $\pm S D, p<0.01={ }^{* *}$, t test.

\section{Figure 7. Nuclear p53 levels correlate with Akt activation}

a-c, A549 and MDA-MB-231 cells after $24 \mathrm{~h}$ of treatment with control vehicle were fixed and processed for IF staining for $\mathrm{p} 53$ and $\mathrm{pAkt}{ }^{\mathrm{S473}}$. The nuclear p53 and $\mathrm{pAkt} \mathrm{S}^{\mathrm{S43}}$ levels were quantified and the correlation between the nuclear p53 and pAkt ${ }^{\mathrm{4} 73}$ was calculated by Pearson's r (b,c). N=120 cells from representative experiments of three repeats. See extended images and quantification in Extended Data Fig. 7b-i. 
d-g, MDA-MB-231 cells were treated with $30 \mu \mathrm{M}$ cisplatin or control vehicle for $24 \mathrm{~h}$ and were then fixed and processed for IF staining of p53 and pFOXO3 ${ }^{5253}$. The nuclear levels of p53 and pFOXO3 ${ }^{\mathrm{S} 253}$ were quantified. The low $(\mathrm{L})$ and high $(\mathrm{H})$ levels of nuclear p53 were determined based on the average of the p53 levels in the corresponding control vehicle or cisplatin-treated groups (e). The correlation between the nuclear p53 and pFOXO3 ${ }^{S 253}$ was determined by Pearson's $r(\mathbf{f}, \mathbf{g}) . \quad \mathrm{N}=120$ cells from representative experiments of three repeats.

h-k, A549 cells were transiently transfected with Flag-tagged mutant $\mathrm{p} 53^{\mathrm{R} 175 \mathrm{H}}$ and then $24 \mathrm{~h}$ later treated with $30 \mu \mathrm{M}$ cisplatin or control vehicle for $4 \mathrm{~h}$. The cells were then fixed and processed for IF staining of Flag-tagged mutant $\mathrm{p} 53$ and $\mathrm{pAkt}^{\mathrm{S473}}$. The nuclear

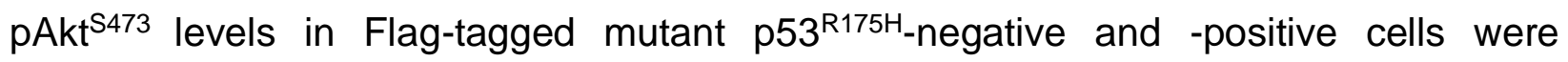
quantified (i). The correlation between the nuclear levels of Flag-tagged mutant $\mathrm{p} 53^{\mathrm{R} 175 \mathrm{H}}$ and $\mathrm{pAkt}^{\mathrm{S473}}$ was determined by Pearson's $r(\mathbf{j}, \mathbf{k}) . \mathrm{N}=30$ cells from representative experiments of three repeats.

I, A schematic model of the stress-induced nuclear p53-phosphoinositide signalosome for Akt activation, DNA-repair, cell survival, and invasion.

For all panels, data are represented as mean $\pm S D, p<0.01={ }^{* *}$, t test. Scale bar: $5 \mu \mathrm{m}$.

\section{SUPPLEMENTAL INFORMATION}

\section{Extended Data Fig. 1 p53 associates with stress-induced active Akt in the nucleus}

a, WB analysis of $\mathrm{pAkt}^{\mathrm{S473}}$ in MDA-MB-231 cells after $24 \mathrm{~h}$ starvation and treatment with $10 \mu \mathrm{M}$ PI3Ka inhibitor alpelisib, $2 \mu \mathrm{M}$ pan-PI3K inhibitor buparlisib, or control vehicle, followed by 5 min stimulation with $50 \mathrm{ng} / \mathrm{ml}$ EGF. $\mathrm{N}=3$. 
b-c, IF staining of pAkt ${ }^{543}$ in MDA-MB-231 cells treated with control vehicle or $30 \mu \mathrm{M}$ cisplatin for $24 \mathrm{~h}$ with or without the presence of the PI3Ka inhibitor alpelisib (10 $\mu \mathrm{M})$ or the pan-PI3K inhibitor buparlisib $(2 \mu \mathrm{M})$. The nuclear pAkt ${ }^{S 473}$ levels were quantified (c). $\mathrm{N}=30$ cells from representative experiments of three repeats.

d-g, IF staining of p53 and pAkt ${ }^{S 473}$ in MDA-MB-231 cells treated with $100 \mu \mathrm{M} t \mathrm{BHQ}, 100$ $\mu \mathrm{M}$ hydroxyurea, $100 \mu \mathrm{M}$ etoposide, $30 \mu \mathrm{M}$ cisplatin, or control vehicle for $24 \mathrm{~h}$. The nuclear levels of $\mathrm{pAkt}^{\mathrm{S47}}(\mathbf{e})$ and p53 (f) and their colocalization (g) were quantified. $\mathrm{N}=30$ cells from representative experiments of three repeats.

h-k, IF staining of p53 and pAkt ${ }^{S 473}$ in A549 and MDA-MB-231 cells treated with $30 \mu \mathrm{M}$ cisplatin or control vehicle for $24 \mathrm{~h}$. The nuclear levels of p53 and pAkt ${ }^{S 473}$ (j) and their colocalization (k) were quantified. $\mathrm{N}=30$ cells from representative experiments of three repeats.

I-n, Two-panel section of IF staining against p53 and pAkt ${ }^{5473}$ in A549 cells treated with $30 \mu \mathrm{M}$ cisplatin or control vehicle for $24 \mathrm{~h}$. The middle section focusing on the nucleus and the bottom section focusing on the cytosol were demonstrated in the model (I). The nuclear and cytosolic colocalization of p53 and pAkt ${ }^{S 473}$ was quantified $(\mathbf{n}) . \mathrm{N}=30$ cells from representative experiments of three repeats.

For all panels, data are represented as mean $\pm S D, p<0.01={ }^{\star *}$, $t$ test. Scale bar: $5 \mu \mathrm{m}$.

\section{Extended Data Fig. 2 p53 associates with the stress-induced nuclear Akt pathway}

a, PLA of p53-Akt/pAkt ${ }^{T 308} / \mathrm{pAkt}^{\mathrm{S} 473}$ in A549 and MDA-MB-231 cells treated with control vehicle or $30 \mu \mathrm{M}$ cisplatin for $24 \mathrm{~h}$. See quantification in Fig. $1 \mathrm{~g}$. 
b, PLA of p53-pAkt ${ }^{\mathrm{S} 73}$ in MDA-MB-231 cells treated with $100 \mu \mathrm{M}$ tBHQ, $100 \mu \mathrm{M}$ hydroxyurea, $100 \mu \mathrm{M}$ etoposide, $30 \mu \mathrm{M}$ cisplatin, or control vehicle for $24 \mathrm{~h}$. The nuclear PLA foci were quantified. $\mathrm{N}=30$ cells from representative experiments of three repeats. c, 3D section of PLA between p53 and pAkt ${ }^{\$ 473}$ overlaid with Lamin A/C in MDA-MB-231 cells treated with control vehicle or $30 \mu \mathrm{M}$ cisplatin for $24 \mathrm{~h}$. Each frame of the 3D sections was over a $0.2 \mu \mathrm{m}$ thickness.

d, IP of p53 and Akt pathway components from MDA-MB-231 cells treated with $30 \mu \mathrm{M}$ cisplatin or control vehicle for $24 \mathrm{~h} . \mathrm{N}=3$.

For all panels, data are represented as mean $\pm S D, p<0.01={ }^{* *}$, $t$ test. Scale bar: $5 \mu \mathrm{m}$.

\section{Extended Data Fig. 3 p53 associates with PDK1 and FOXOs in the nucleus}

a, PLA of p53-pPDK1 ${ }^{\mathrm{S24}} / \mathrm{pPDK}^{\mathrm{S} 396}$ in A549 and MDA-MB-231 cells treated with control vehicle or $30 \mu \mathrm{M}$ cisplatin for $24 \mathrm{~h}$. See quantification in Fig. $2 \mathrm{e}$.

b, PLA of p53-FOXOs in A549 and MDA-MB-231 cells treated with vehicle or $30 \mu \mathrm{M}$ cisplatin for $24 \mathrm{~h}$. See quantification in Fig. 3g.

For all panels, scale bar: $5 \mu \mathrm{m}$.

\section{Extended Data Fig. 4 p53 associates with PI4,5P2 and PI3,4,5 $\mathrm{P}_{3}$ in the nucleus}

a-c, IF staining against $\mathrm{p} 53$ and $\mathrm{PI} 3,4,5 \mathrm{P}_{3}$ in MDA-MB-231 cells treated with $30 \mu \mathrm{M}$ cisplatin or control vehicle for $24 \mathrm{~h}$. The nuclear level of $\mathrm{PI}_{3}, 4,5 \mathrm{P}_{3}(\mathbf{b})$ and its colocalization with p53 (c) were quantified. $\mathrm{N}=30$ cells from representative experiments of three repeats. d-e, PLA of p53-PI4,5P2/PI3,4,5P in A549, MCF-10A, MDA-MB-231, and SUM1315 cells treated with $30 \mu \mathrm{M}$ cisplatin or control vehicle for $24 \mathrm{~h}$. The nuclear PLA foci were quantified (e). $\mathrm{N}=30$ cells from representative experiments of three repeats. 
f-h, PLA of p53-PI4,5P2/PI3,4,5P 3 in MDA-MB-231 cells treated with $100 \mu \mathrm{M}$ tBHQ, 100 $\mu \mathrm{M}$ hydroxyurea, $100 \mu \mathrm{M}$ etoposide, $30 \mu \mathrm{M}$ cisplatin, or control vehicle for $24 \mathrm{~h}$. The nuclear PLA foci were quantified $(\mathbf{g}, \mathbf{h}) . \mathrm{N}=30$ cells from representative experiments of three repeats.

i-j, PLA of p53-PI3,4,5P 3 in MDA-MB-231 cells treated with control vehicle or $30 \mu \mathrm{M}$ cisplatin with or without the presence of the PI3Ka inhibitor alpelisib $(10 \mu \mathrm{M})$, the panPI3K inhibitor buparlisib $(2 \mu \mathrm{M})$, or the PIPKIa inhibitor ISA-2011B (50 $\mu \mathrm{M})$ for $24 \mathrm{~h}$. The nuclear PLA foci were quantified (j). $\mathrm{N}=30$ cells from representative experiments of three repeats.

k, 3D section of PLA between $p 53$ and $P I 3,4,5 P_{3}$ overlaid with Lamin $A / C$ in MDA-MB231 cells treated with control vehicle or $30 \mu \mathrm{M}$ cisplatin treatment for $24 \mathrm{~h}$. Each frame of the 3D sections was over a $0.2 \mu \mathrm{m}$ thickness.

For all panels, data are represented as mean $\pm S D, p<0.01={ }^{* *}$, $t$ test. Scale bar: $5 \mu$.

\section{Extended Data Fig. 5 IPMK and PTEN associate with p53 and mediate p53-bound $\mathrm{PI} 4,5 \mathrm{P}_{2}$ and $\mathrm{PI}, 4,5 \mathrm{P}_{3}$ interconversion in the nucleus}

a-c, IF staining against p53 and IPMK in MDA-MB-231 cells treated with $30 \mu \mathrm{M}$ cisplatin or control vehicle for $24 \mathrm{~h}$. The nuclear level of IPMK (b) and its colocalization with p53 (c) were quantified. $\mathrm{N}=30$ cells from representative experiments of three repeats.

d-g, IF staining against p53 and PTEN in A549 or MDA-MB-231 cells treated with $30 \mu \mathrm{M}$ cisplatin or control vehicle for $24 \mathrm{~h}$. The nuclear level of PTEN (f) and its colocalization with p53 (g) were quantified. $\mathrm{N}=30$ cells from representative experiments of three repeats. 
h-j, PLA of p53-IPMK/PTEN in A549 and MDA-MB-231 cells treated with control vehicle or $30 \mu \mathrm{M}$ cisplatin for $24 \mathrm{~h}$. The nuclear PLA foci were quantified $(\mathbf{i}, \mathbf{j})$. $\mathrm{N}=30$ cells from representative experiments of three repeats.

k-I, PLA of $\mathrm{p} 53-\mathrm{PI}, 5 \mathrm{P}_{2} / \mathrm{PI}_{3}, 4,5 \mathrm{P}_{3}$ in MDA-MB-231 cells $48 \mathrm{~h}$ after of transient transfection with control siRNAs or siRNAs against PIPKIa, IPMK, and PTEN (k). See quantification in Fig. 4h,i. The knockdown efficiency was validated by WB (I).

For all panels, data are represented as mean $\pm S D, p<0.01={ }^{* *}$, t test. Scale bar: $5 \mu \mathrm{m}$.

\section{Extended Data Fig. 6 Nuclear FOXO and PDK1 phosphorylation are mediated by the p53-PI signalosome}

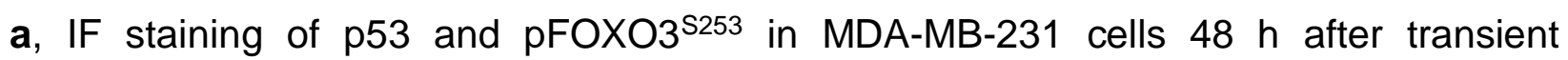
transfection with control siRNAs or siRNAs against p53, PIPKIa, IPMK, and PTEN. The nuclear pFOXO3 ${ }^{\mathrm{S} 253}$ levels were quantified. $\mathrm{N}=30$ cells from representative experiments of three repeats.

b, MDA-MB-231 cells were transfected with control siRNAs or siRNAs against p53, PIPKIa, IPMK, and PTEN. 24 h later, cells were treated with $30 \mu \mathrm{M}$ cisplatin or control vehicle for $24 \mathrm{~h}$ before being processed for PLA between p53 and pFOXO3 ${ }^{\mathrm{S} 253}$. The nuclear PLA foci were quantified. $\mathrm{N}=30$ cells from representative experiments of three repeats.

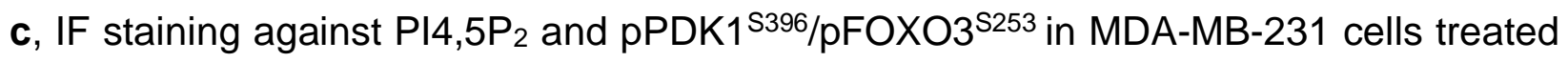
with $30 \mu \mathrm{M}$ cisplatin or control vehicle for $24 \mathrm{~h}$. See Fig. 6a,b for the nuclear region and quantification of the nuclear colocalization of $\mathrm{PI} 4,5 \mathrm{P} 2$ and $\mathrm{pPDK} 1^{\mathrm{s} 396} / \mathrm{pFOXO3^{ \textrm {S } 2 5 3 }}$.

For all panels, data are represented as mean $\pm S D, p<0.01={ }^{* *}$, t test. Scale bar: $5 \mu$ m. 


\section{Extended Data Fig. 7 p53 and active Akt target to DNA damage sites in the}

\section{nucleus}

a, STED super-resolution images of IF staining against p53, pAkt ${ }^{S 47}$, and the DNA DSB marker $\mathrm{X}-\mathrm{H} 2 \mathrm{~A} . \mathrm{X}$ in MDA-MB-231 and A549 cells treated with $30 \mu \mathrm{M}$ cisplatin or control vehicle for 24 h. See quantification in Fig. $6 d$.

b-e, A549 cells were treated with $30 \mu \mathrm{M}$ cisplatin or control vehicle for $24 \mathrm{~h}$ and then were fixed and processed for IF staining of p53 and pAkt ${ }^{5473}$. The nuclei were counter-stained by DAPI. The nuclear levels of p53 and pAkt ${ }^{S 473}$ were quantified. The low $(\mathrm{L})$ and high $(\mathrm{H})$ levels of nuclear p53 were determined based on the average p53 levels in the corresponding control vehicle- or cisplatin-treated groups (c). The correlation between nuclear p53 and pAkt ${ }^{S 473}$ was determined by Pearson's $r(\mathbf{d}, \mathbf{e}) . \quad \mathrm{N}=120$ cells from representative experiments of three repeats.

$\mathbf{f - i}, \mathrm{MDA}-\mathrm{MB}-231$ cells were treated with $30 \mu \mathrm{M}$ cisplatin or control vehicle for $24 \mathrm{~h}$ and then fixed and processed for IF staining against p53 and pAkt ${ }^{\mathrm{S43}}$. The nuclei were counter-stained by DAPI. The nuclear levels of $\mathrm{p53}$ and $\mathrm{pAkt} \mathrm{S473}^{\mathrm{s}}$ were quantified. The low $(\mathrm{L})$ and high $(\mathrm{H})$ levels of nuclear p53 were determined based on the average of the p53 levels in the corresponding control vehicle or cisplatin-treated groups $(\mathbf{g})$. The correlation between the nuclear $\mathrm{p53}$ and pAkt ${ }^{\mathrm{S473}}$ was determined by Pearson's $r(\mathbf{h}, \mathbf{i}) . \mathrm{N}=120$ cells from representative experiments of three repeats.

For all panels, data are represented as mean $\pm S D, p<0.01={ }^{\star *}$, t test. Scale bar: $5 \mu \mathrm{m}$. 


\section{Extended Data Table 1}

The binding affinity of the nuclear p53-PI signalosome components with p53

The interaction of recombinant fluorescently-labeled p53 and non-labeled signalosome components was quantitated by microscale thermophoresis (MST) assay. A constant concentration of fluorescently-labeled p53 (target, $5 \mathrm{nM}$ ) was incubated with increasing concentrations of non-labeled ligands to calculate the binding affinity. The binding affinity determined by MST are shown as indicated $\mathrm{K}_{d}$ values. MST was performed using a Monolith NT.115 pico, and the binding affinity was auto-generated by MO. Control v1.6 software. Data are represented as mean $\pm S D ; n=3$.

\section{Extended Data Video 1}

\section{D reconstitution of the p53-pAkt ${ }^{\mathrm{S} 43}$ complex in the nucleoplasm of MDA-MB-231} cells under basal conditions

MDA-MB-231 cells were treated with control vehicle for $24 \mathrm{~h}$ before being processed for PLA between p53 and pAkt ${ }^{S 473}$ (Red). Lamin A/C stained the nuclear envelopes (Green), and the nuclei were counter-stained by DAPI (Blue). The z-stack images were taken with a Leica SP8 confocal microscope with each frame over a $0.2 \mu \mathrm{m}$ thickness. The video of the 3D reconstitution of a representative cell from three independent experiments was generated by LASX. 


\section{Extended Data Video 2}

\section{D reconstitution of the p53-pAkt ${ }^{\mathrm{S473}}$ complex in the nucleoplasm of MDA-MB-231}

\section{cells under stress}

MDA-MB-231 cells were treated with $30 \mu \mathrm{M}$ cisplatin for $24 \mathrm{~h}$ before being processed for PLA between p53 and pAkt ${ }^{\mathrm{S} 473}$ (Red). Lamin A/C stained the nuclear envelopes (Green), and the nuclei were counter-stained by DAPI (Blue). The z-stack images were taken with a Leica SP8 confocal microscope with each frame over a $0.2 \mu \mathrm{m}$ thickness. The video of the 3D reconstitution of a representative cell from three independent experiments was generated by LASX.

\section{REFERENCES}

1. Fruman, D.A. et al. The PI3K Pathway in Human Disease. Cell 170, 605-635 (2017).

2. Hoxhaj, G. \& Manning, B.D. The PI3K-AKT network at the interface of oncogenic signalling and cancer metabolism. Nat Rev Cancer 20, 74-88 (2020).

3. Manning, B.D. \& Toker, A. AKT/PKB Signaling: Navigating the Network. Cell 169, 381-405 (2017).

4. Stokoe, D. et al. Dual role of phosphatidylinositol-3,4,5-trisphosphate in the activation of protein kinase B. Science 277, 567-570 (1997).

5. Alessi, D.R. et al. Characterization of a 3-phosphoinositide-dependent protein kinase which phosphorylates and activates protein kinase Balpha. Curr Biol 7, 261-269 (1997).

6. Sarbassov, D.D., Guertin, D.A., Ali, S.M. \& Sabatini, D.M. Phosphorylation and regulation of Akt/PKB by the rictor-mTOR complex. Science 307, 1098-1101 (2005).

7. Thapa, N., Horn, H.T. \& Anderson, R.A. Phosphoinositide spatially free AKT/PKB activation to all membrane compartments. Adv Biol Regul 72, 1-6 (2019).

8. Martelli, A.M. et al. The emerging multiple roles of nuclear Akt. Biochim Biophys Acta 1823, 2168-2178 (2012).

9. Meier, R., Alessi, D.R., Cron, P., Andjelkovic, M. \& Hemmings, B.A. Mitogenic activation, phosphorylation, and nuclear translocation of protein kinase Bbeta. $J$ Biol Chem 272, 30491-30497 (1997).

10. Andjelkovic, M. et al. Role of translocation in the activation and function of protein kinase B. J Biol Chem 272, 31515-31524 (1997).

11. Borgatti, P. et al. Threonine 308 phosphorylated form of Akt translocates to the nucleus of PC12 cells under nerve growth factor stimulation and associates with the nuclear matrix protein nucleolin. J Cell Physiol 196, 79-88 (2003).

12. Wang, R. \& Brattain, M.G. AKT can be activated in the nucleus. Cell Signal 18, 17221731 (2006). 
13. Bozulic, L., Surucu, B., Hynx, D. \& Hemmings, B.A. PKBalpha/Akt1 acts downstream of DNA-PK in the DNA double-strand break response and promotes survival. Mol Cell 30, 203-213 (2008).

14. Boehme, K.A., Kulikov, R. \& Blattner, C. p53 stabilization in response to DNA damage requires Akt/PKB and DNA-PK. Proc Natl Acad Sci U S A 105, 7785-7790 (2008).

15. Muller, P.A. \& Vousden, K.H. p53 mutations in cancer. Nat Cell Biol 15, 2-8 (2013).

16. Kastenhuber, E.R. \& Lowe, S.W. Putting p53 in Context. Cell 170, 1062-1078 (2017).

17. Choi, S., Chen, M., Cryns, V.L. \& Anderson, R.A. A nuclear phosphoinositide kinase complex regulates p53. Nat Cell Biol 21, 462-475 (2019).

18. $\mathrm{Xu}, \mathrm{R}$. et al. Inositol polyphosphate multikinase is a coactivator of p53-mediated transcription and cell death. Sci Signal 6, ra22 (2013).

19. Freeman, D.J. et al. PTEN tumor suppressor regulates p53 protein levels and activity through phosphatase-dependent and -independent mechanisms. Cancer Cell 3, 117-130 (2003).

20. Blind, R.D., Suzawa, M. \& Ingraham, H.A. Direct modification and activation of a nuclear receptor-PIP(2) complex by the inositol lipid kinase IPMK. Sci Signal 5, ra44 (2012).

21. Blind, R.D. et al. The signaling phospholipid PIP3 creates a new interaction surface on the nuclear receptor SF-1. Proc Natl Acad Sci U S A 111, 15054-15059 (2014).

22. Huang, Y. et al. Global tumor protein p53/p63 interactome: making a case for cisplatin chemoresistance. Cell Cycle 11, 2367-2379 (2012).

23. Liu, Q., Turner, K.M., Alfred Yung, W.K., Chen, K. \& Zhang, W. Role of AKT signaling in DNA repair and clinical response to cancer therapy. Neuro Oncol 16, 1313-1323 (2014).

24. Mayer, I.A. \& Arteaga, C.L. The PI3K/AKT Pathway as a Target for Cancer Treatment. Annu Rev Med 67, 11-28 (2016).

25. Casamayor, A., Morrice, N.A. \& Alessi, D.R. Phosphorylation of Ser-241 is essential for the activity of 3-phosphoinositide-dependent protein kinase-1: identification of five sites of phosphorylation in vivo. Biochem J 342 ( Pt 2), 287-292 (1999).

26. Moon, Z., Wang, Y., Aryan, N., Mousseau, D.D. \& Scheid, M.P. Serine 396 of PDK1 is required for maximal PKB activation. Cell Signal 20, 2038-2049 (2008).

27. Liu, P. et al. PtdIns(3,4,5)P3-Dependent Activation of the mTORC2 Kinase Complex. Cancer Discov 5, 1194-1209 (2015).

28. Chung, Y.M. et al. FOXO3 signalling links ATM to the p53 apoptotic pathway following DNA damage. Nat Commun 3, 1000 (2012).

29. Wang, F. et al. Biochemical and structural characterization of an intramolecular interaction in FOXO3a and its binding with p53. J Mol Biol 384, 590-603 (2008).

30. Fu, W. et al. MDM2 acts downstream of p53 as an E3 ligase to promote FOXO ubiquitination and degradation. J Biol Chem 284, 13987-14000 (2009).

31. Webb, A.E. \& Brunet, A. FOXO transcription factors: key regulators of cellular quality control. Trends Biochem Sci 39, 159-169 (2014).

32. Semenas, J. et al. The role of PI3K/AKT-related PIP5K1alpha and the discovery of its selective inhibitor for treatment of advanced prostate cancer. Proc Natl Acad Sci US A 111, E3689-3698 (2014).

33. Currie, R.A. et al. Role of phosphatidylinositol 3,4,5-trisphosphate in regulating the activity and localization of 3-phosphoinositide-dependent protein kinase-1. Biochem J 337 ( Pt 3), 575-583 (1999). 
34. Calleja, V. et al. Intramolecular and intermolecular interactions of protein kinase B define its activation in vivo. PLoS Biol 5, e95 (2007).

35. Ebner, M., Lucic, I., Leonard, T.A. \& Yudushkin, I. PI(3,4,5)P3 Engagement Restricts Akt Activity to Cellular Membranes. Mol Cell 65, 416-431 e416 (2017).

36. Chen, M. et al. The nuclear phosphoinositide response to stress. Cell Cycle 19, 268-289 (2020).

37. Barlow, C.A., Laishram, R.S. \& Anderson, R.A. Nuclear phosphoinositides: a signaling enigma wrapped in a compartmental conundrum. Trends Cell Biol 20, 25-35 (2010).

38. Boronenkov, I.V., Loijens, J.C., Umeda, M. \& Anderson, R.A. Phosphoinositide signaling pathways in nuclei are associated with nuclear speckles containing pre-mRNA processing factors. Mol Biol Cell 9, 3547-3560 (1998).

39. Wang, Y.H. et al. DNA damage causes rapid accumulation of phosphoinositides for ATR signaling. Nat Commun 8, 2118 (2017).

40. Sharma, A., Singh, K. \& Almasan, A. Histone H2AX phosphorylation: a marker for DNA damage. Methods Mol Biol 920, 613-626 (2012).

41. Schober, P., Boer, C. \& Schwarte, L.A. Correlation Coefficients: Appropriate Use and Interpretation. Anesth Analg 126, 1763-1768 (2018).

42. Cocco, L. et al. Synthesis of polyphosphoinositides in nuclei of Friend cells. Evidence for polyphosphoinositide metabolism inside the nucleus which changes with cell differentiation. Biochem J 248, 765-770 (1987).

43. Davis, W.J., Lehmann, P.Z. \& Li, W. Nuclear PI3K signaling in cell growth and tumorigenesis. Front Cell Dev Biol 3, 24 (2015).

44. Kikani, C.K. et al. Proliferative and antiapoptotic signaling stimulated by nuclearlocalized PDK1 results in oncogenesis. Sci Signal 5, ra80 (2012).

45. Shiraishi, I. et al. Nuclear targeting of Akt enhances kinase activity and survival of cardiomyocytes. Circ Res 94, 884-891 (2004).

46. Fu, W. \& Hall, M.N. Regulation of mTORC2 Signaling. Genes (Basel) 11 (2020).

47. Tzivion, G., Dobson, M. \& Ramakrishnan, G. FoxO transcription factors; Regulation by AKT and 14-3-3 proteins. Biochim Biophys Acta 1813, 1938-1945 (2011).

48. Zhang, X., Tang, N., Hadden, T.J. \& Rishi, A.K. Akt, FoxO and regulation of apoptosis. Biochim Biophys Acta 1813, 1978-1986 (2011).

49. Hanel, W. et al. Two hot spot mutant p53 mouse models display differential gain of function in tumorigenesis. Cell Death Differ 20, 898-909 (2013).

50. Iggo, R., Gatter, K., Bartek, J., Lane, D. \& Harris, A.L. Increased expression of mutant forms of p53 oncogene in primary lung cancer. Lancet 335, 675-679 (1990).

51. Yemelyanova, A. et al. Immunohistochemical staining patterns of p53 can serve as a surrogate marker for TP53 mutations in ovarian carcinoma: an immunohistochemical and nucleotide sequencing analysis. Mod Pathol 24, 1248-1253 (2011).

52. Muller, P.A. et al. Mutant p53 drives invasion by promoting integrin recycling. Cell 139, 1327-1341 (2009).

53. Andre, F. et al. Alpelisib for PIK3CA-Mutated, Hormone Receptor-Positive Advanced Breast Cancer. N Engl J Med 380, 1929-1940 (2019).

54. Mellman, D.L. et al. A PtdIns4,5P2-regulated nuclear poly(A) polymerase controls expression of select mRNAs. Nature 451, 1013-1017 (2008).

55. Malin, D., Chen, F., Schiller, C., Koblinski, J. \& Cryns, V.L. Enhanced metastasis suppression by targeting TRAIL receptor 2 in a murine model of triple-negative breast cancer. Clin Cancer Res 17, 5005-5015 (2011). 
56. Choi, S. et al. Agonist-stimulated phosphatidylinositol-3,4,5-trisphosphate generation by scaffolded phosphoinositide kinases. Nat Cell Biol 18, 1324-1335 (2016).

57. Asmari, M., Ratih, R., Alhazmi, H.A. \& El Deeb, S. Thermophoresis for characterizing biomolecular interaction. Methods 146, 107-119 (2018).

58. Costes, S.V. et al. Automatic and quantitative measurement of protein-protein colocalization in live cells. Biophys $\boldsymbol{J}$ 86, 3993-4003 (2004).

59. Chen, M., Horn, H.T., Wen, T., Cryns, V.L. \& Anderson, R.A. Assessing In Situ Phosphoinositide-Protein Interactions Through Fluorescence Proximity Ligation Assay in Cultured Cells. Methods Mol Biol 2251, 133-142 (2021). 
Fig. 1 a MDA-MB-231(R280K)

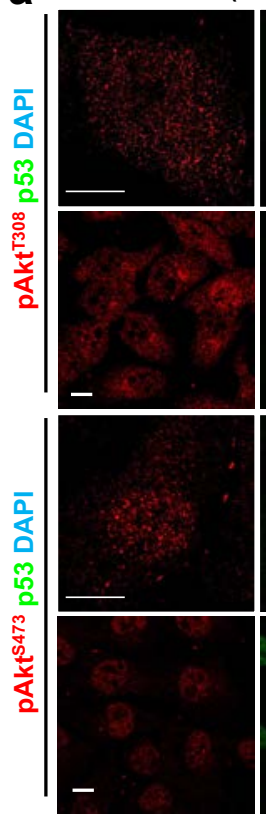

d
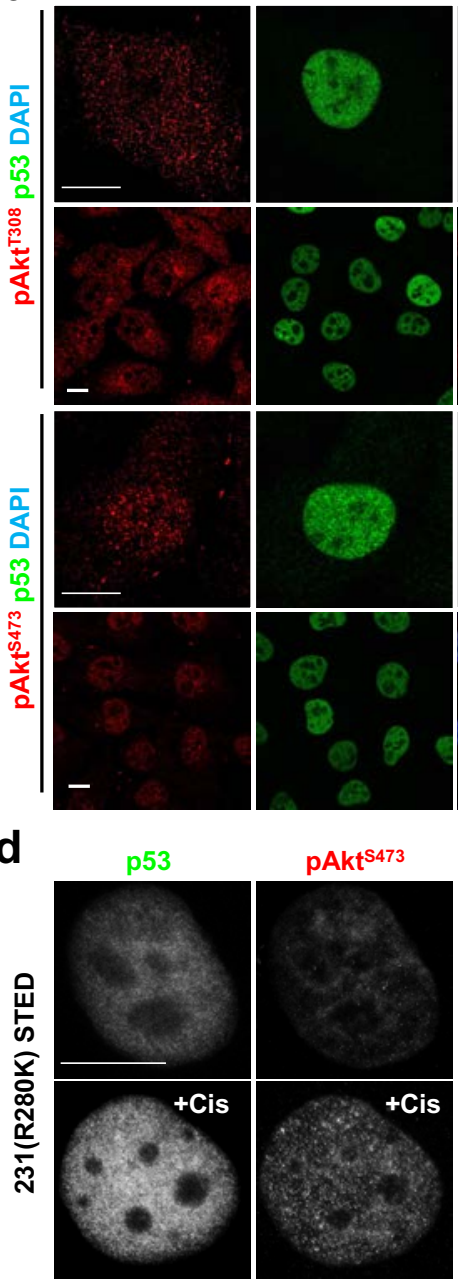

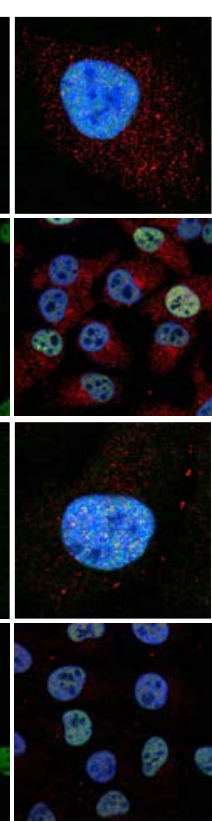

Merge

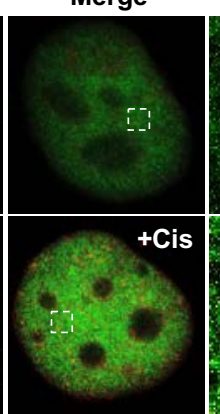

MDA-MB-231(R280K) Input $\mathrm{P} \cdot 19^{\mathrm{G}}$ IP: Akt

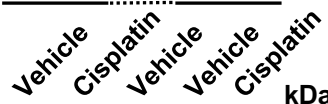

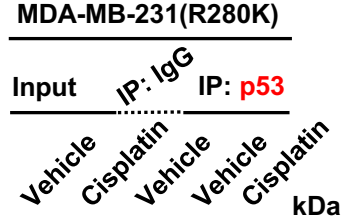
Akt $-55$ p53 p53
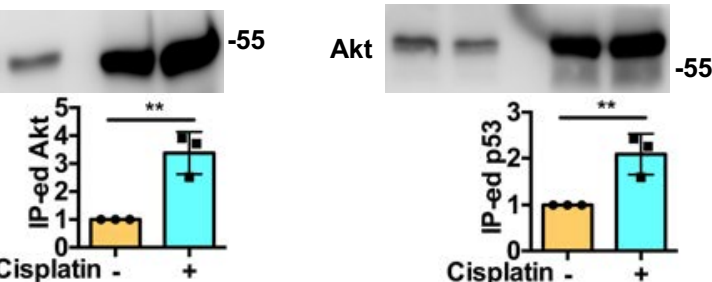

MDA-MB-231(R280K)

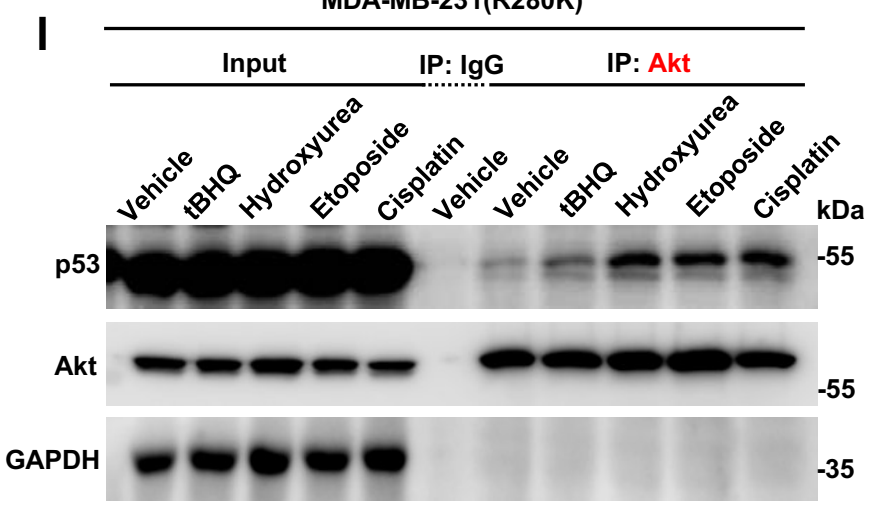

Cisplatin
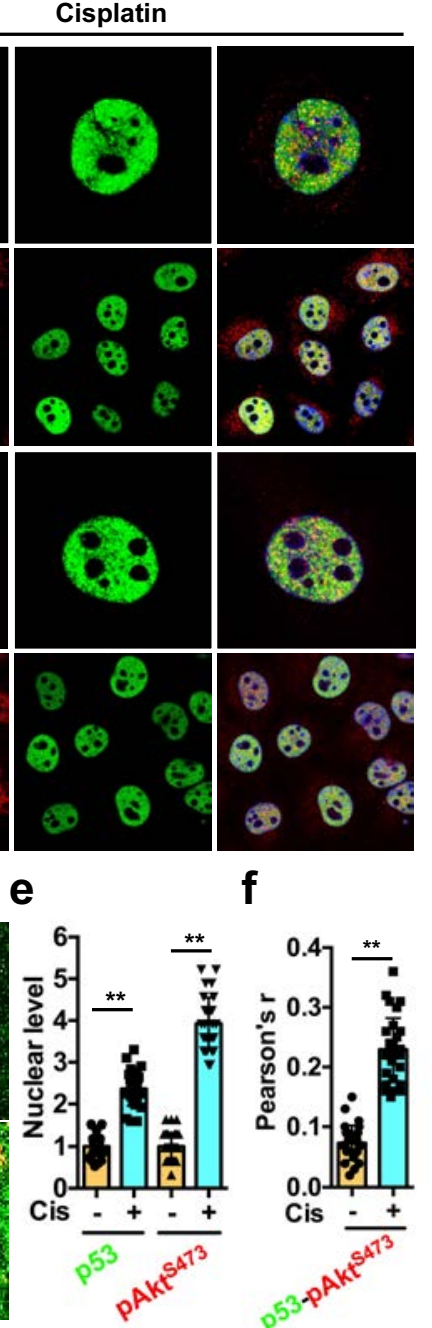

$$
\text { k }
$$

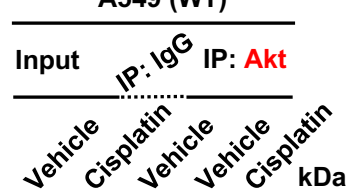

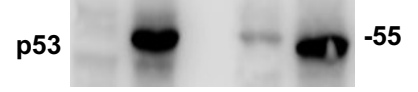

Akt -55

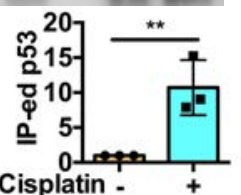

m

In vitro binding

IP-p53

p53 $(\mu \mathrm{g}) \begin{array}{llllll}1 & 1 & 1 & 1 & 1 & 1\end{array}$

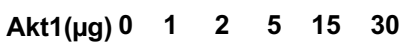

Akt1

19

p53 - 1 a

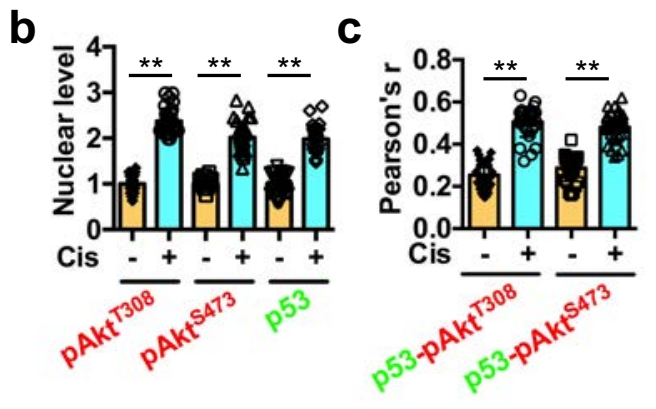

g
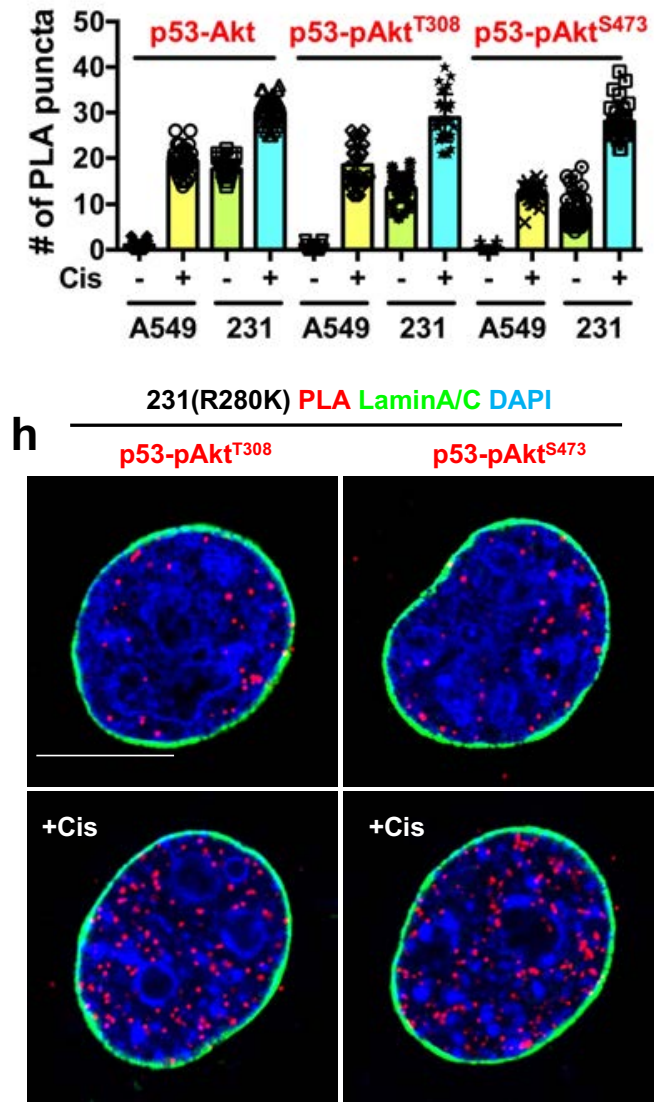

n

MDA-MB-231(R280K)
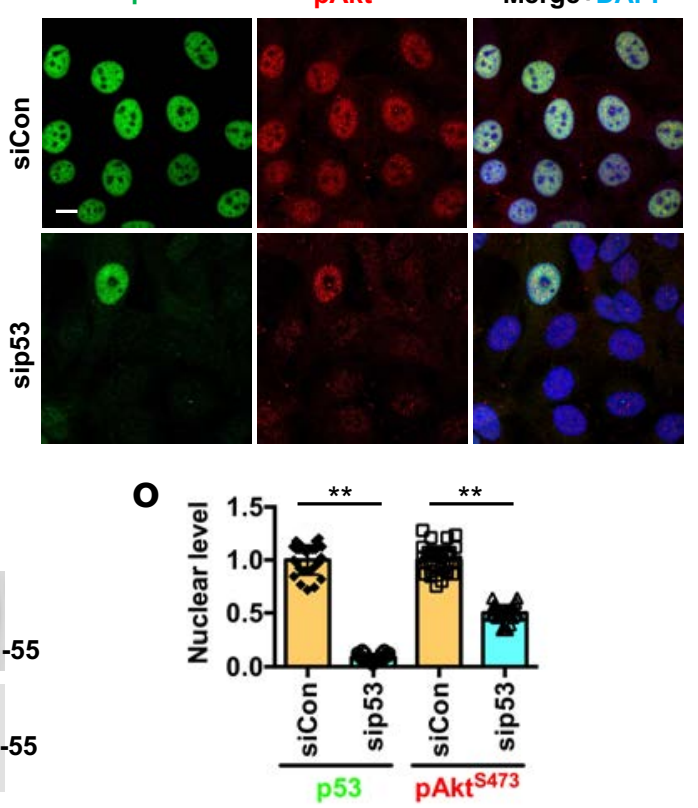
Fig. 2

a MDA-MB-231(R280K)

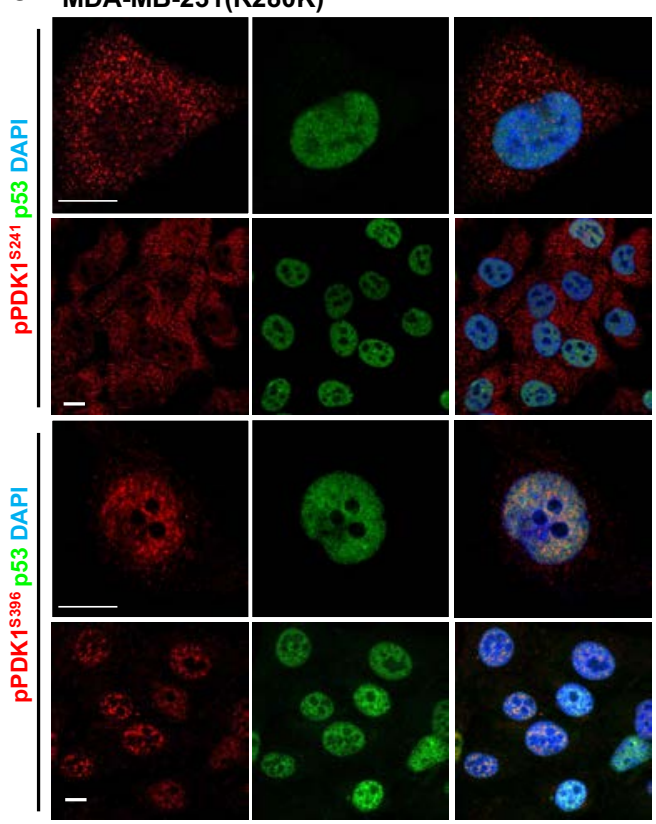

Cisplatin

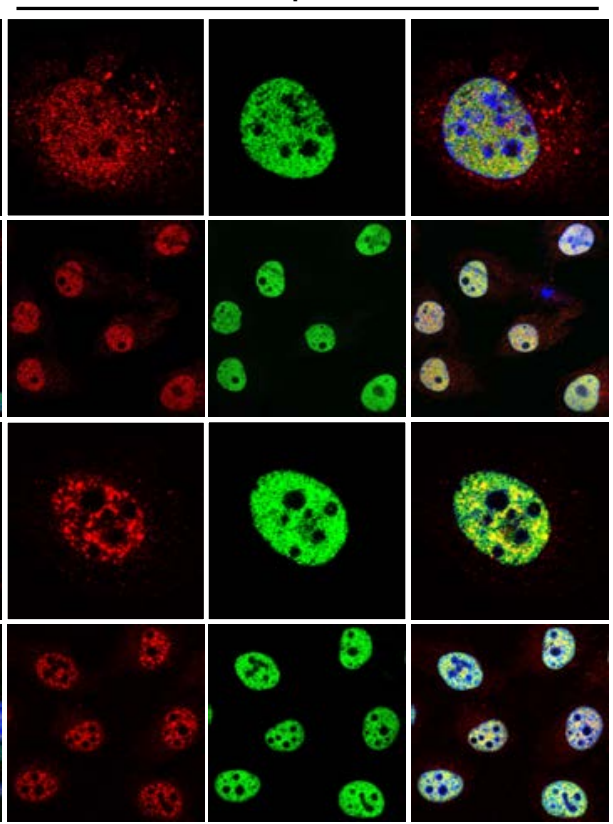

b

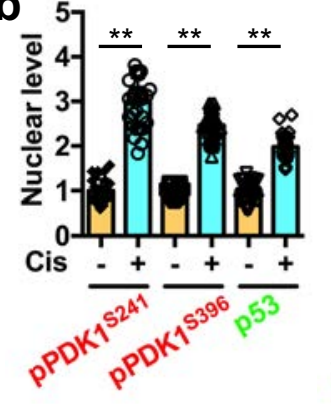

C



K



d



g
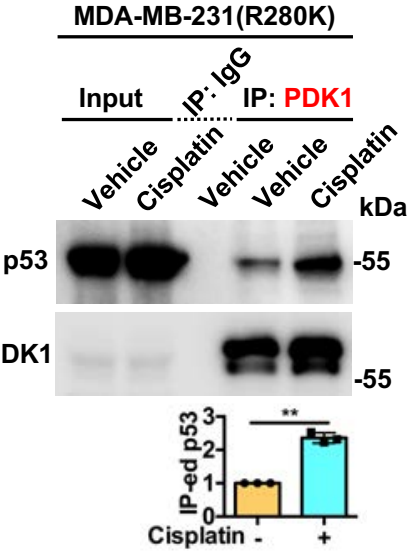

MDA-MB-231(R280K)

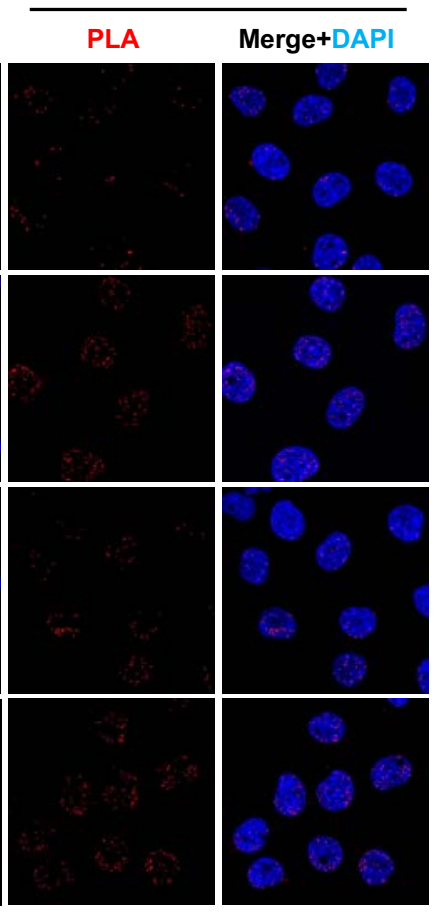

h

h $\quad$ A549 (WT) Input ...... IP: PDK1
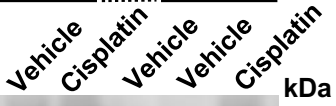

p53

PDK1
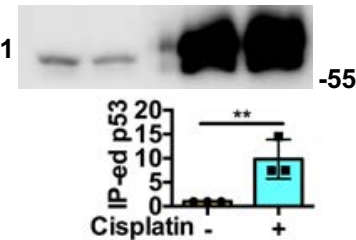

e

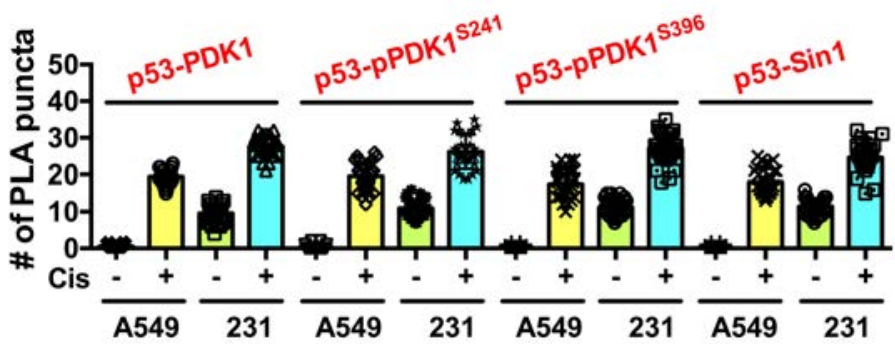

f

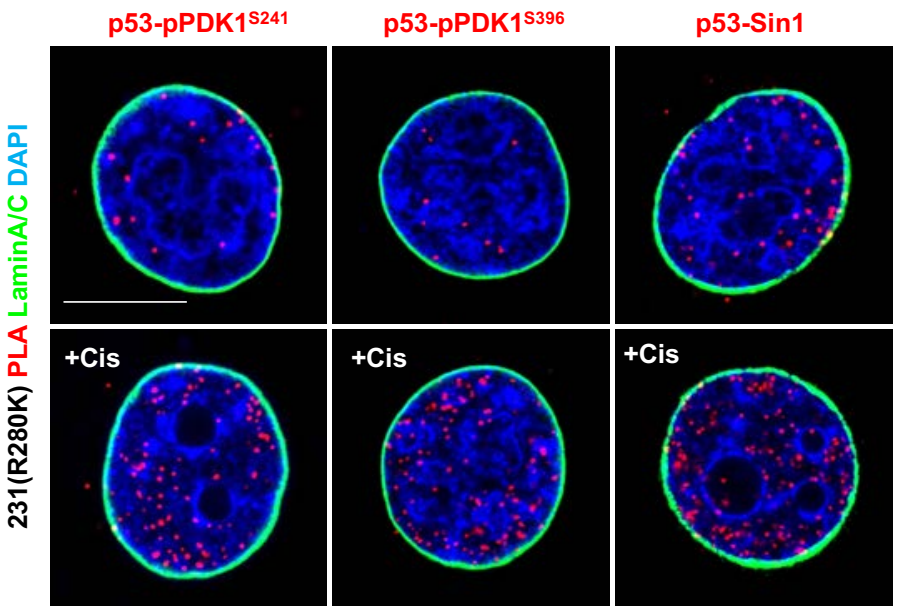

MDA-MB-231(R280K) Input $\$ .0^{0}$ IP: $\operatorname{Sin} 1$
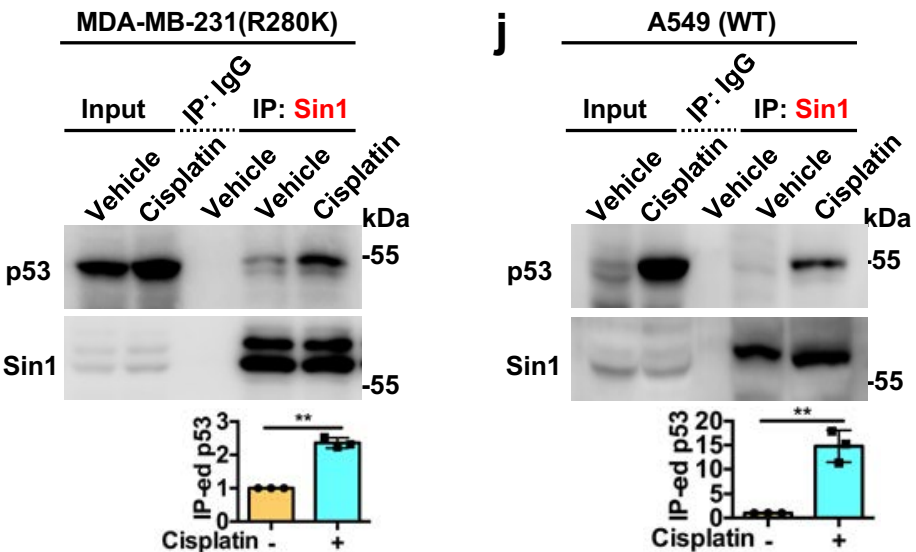
Fig. 3

a

\begin{tabular}{|c|c|c|c|c|c|}
\hline \multicolumn{6}{|c|}{ Akt phosphorylation sites } \\
\hline & & DBD & NLS & NES & $\overline{T D}$ \\
\hline F0X01 & T24 & & S256 & S319 & \\
\hline FOXO3 & T32 & & S253 & S315 & \\
\hline FOXO4 & T28 & & S193 & S258 & \\
\hline F0X06 & T26 & & S184 & & \\
\hline
\end{tabular}

b


e

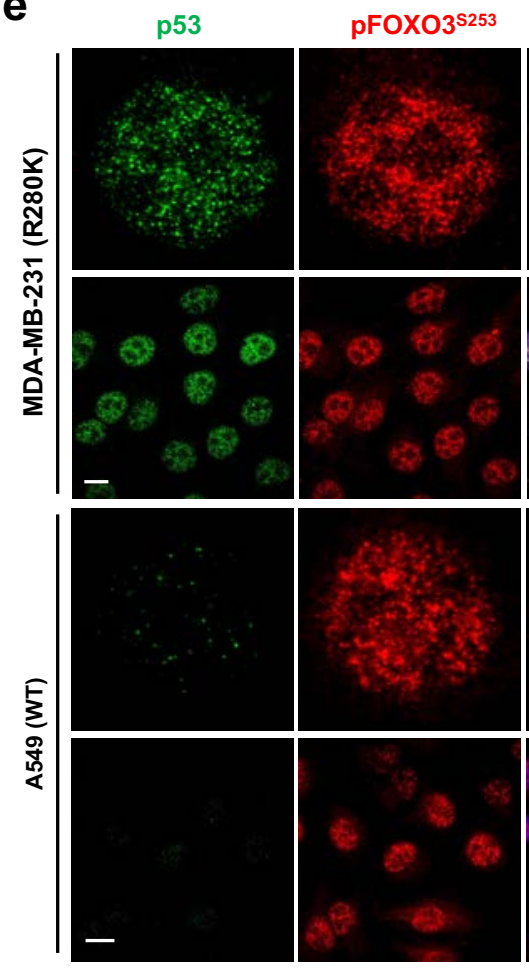

\section{g}

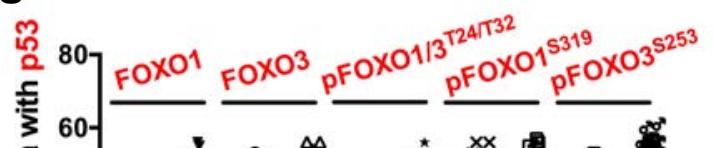



言 40

$₫ 20-$

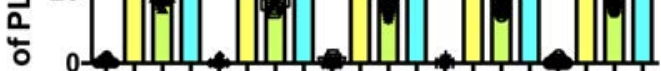

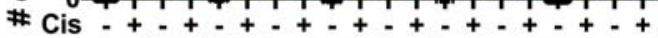
$A^{5^{4^{9}}} 2^{3^{1}} A^{5^{4^{9}}} 2^{3^{1}} a^{5^{4^{9}}} 2^{3^{1}} A^{5^{4^{9}}} 2^{3^{1}} a^{5^{4^{9}}} 2^{3^{1}}$ d กू้ $^{3}$

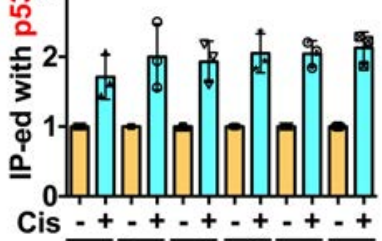

pata f

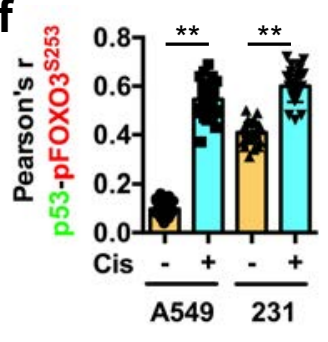

Cisplatin

Cisplatin
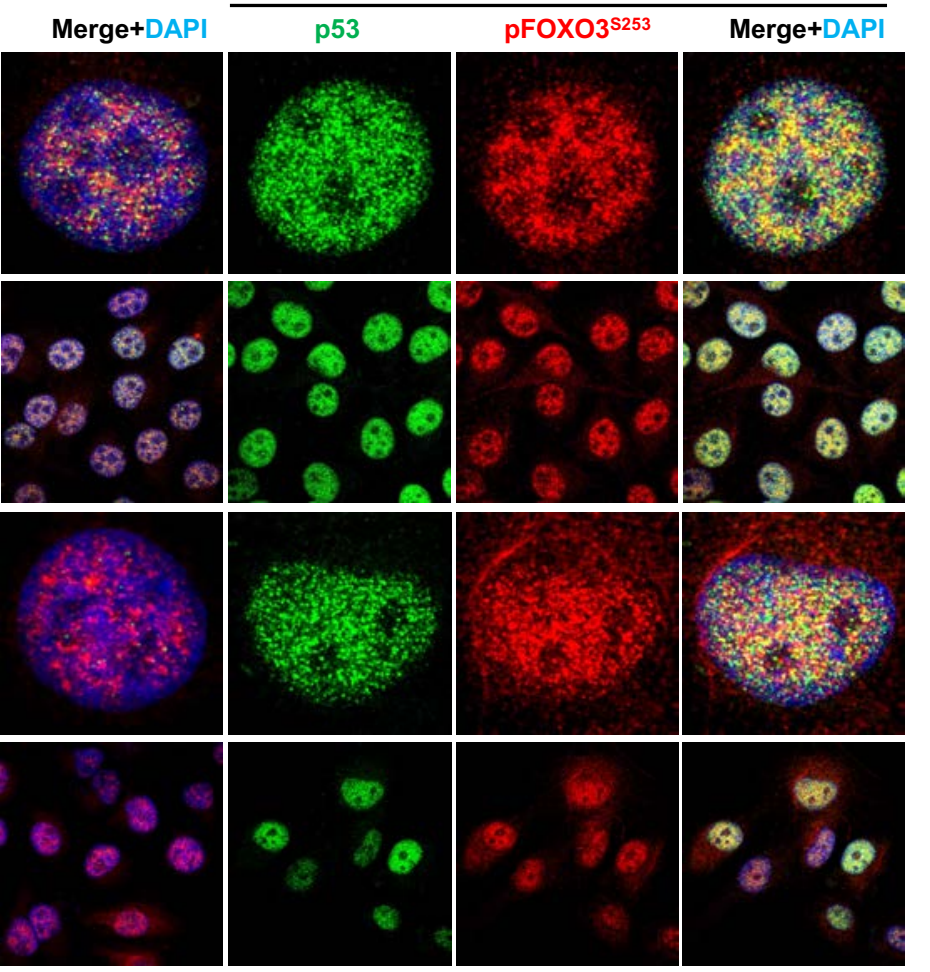

i MDA-MB-231(R280K)
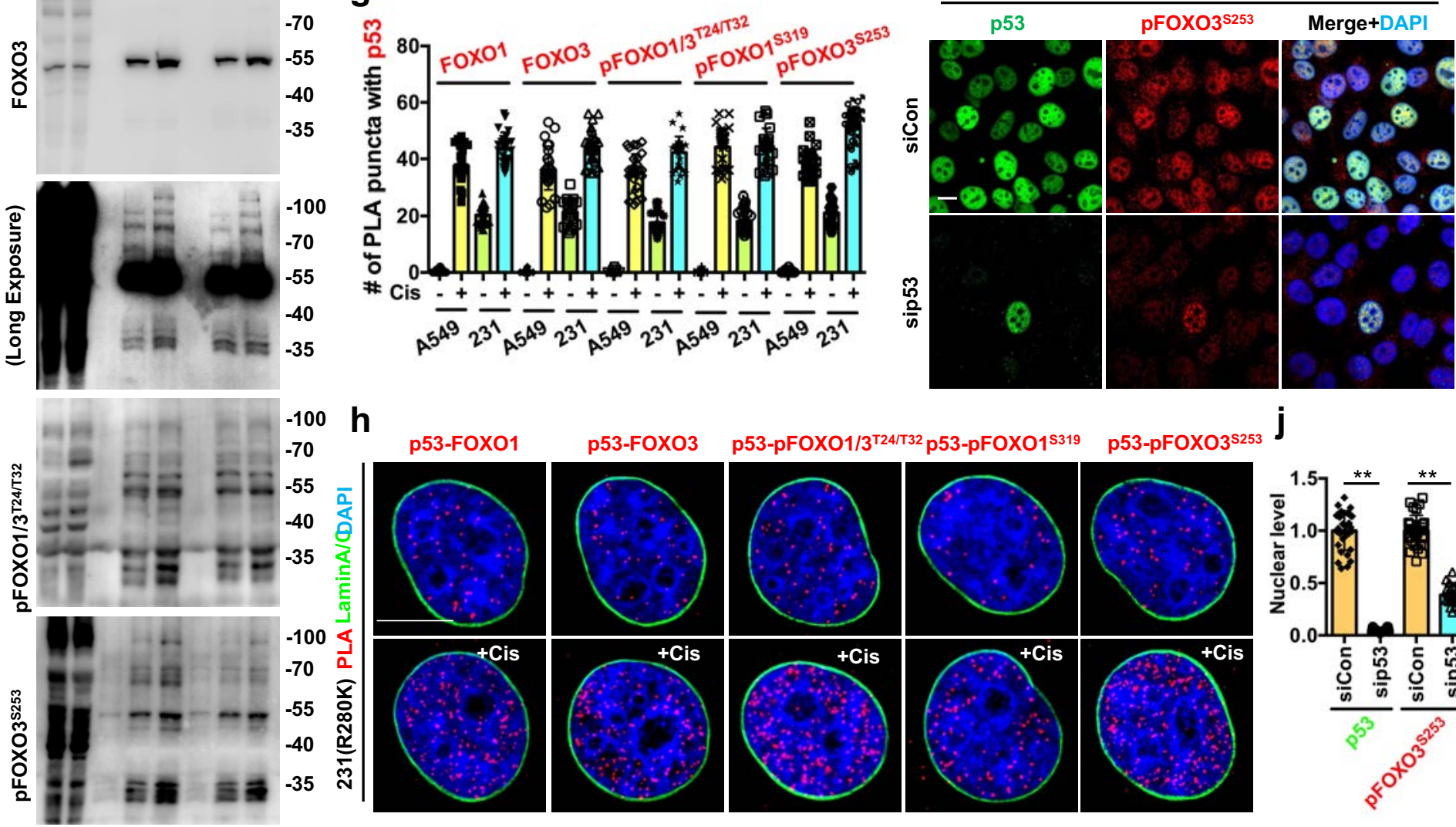

h

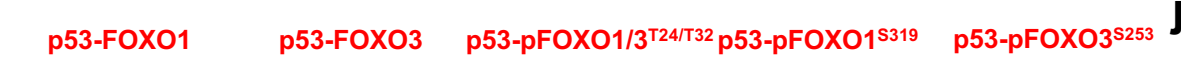
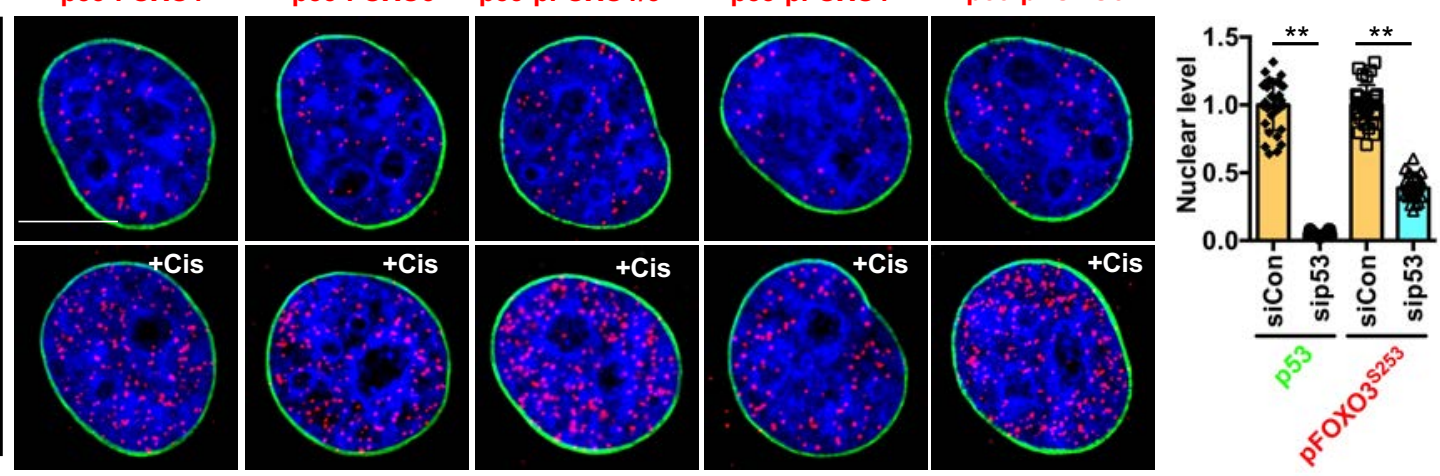
Fig. 4

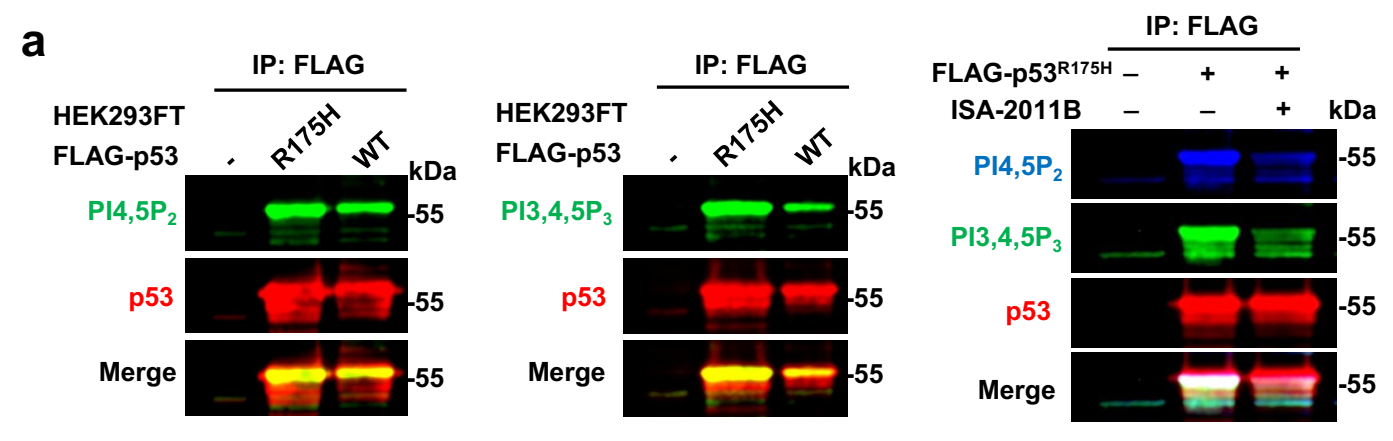

b IP: $\operatorname{lgG} \quad$ IP: $p 53$

HCT116 (WT) Cal33 (R175H)

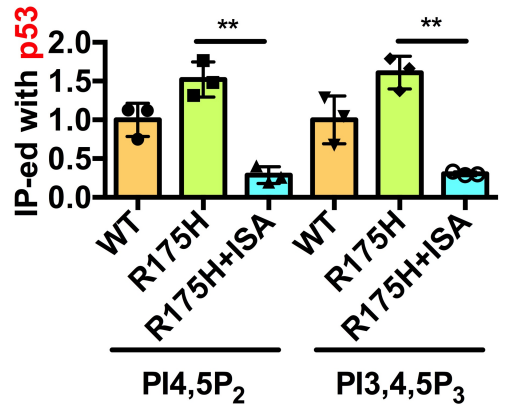

g

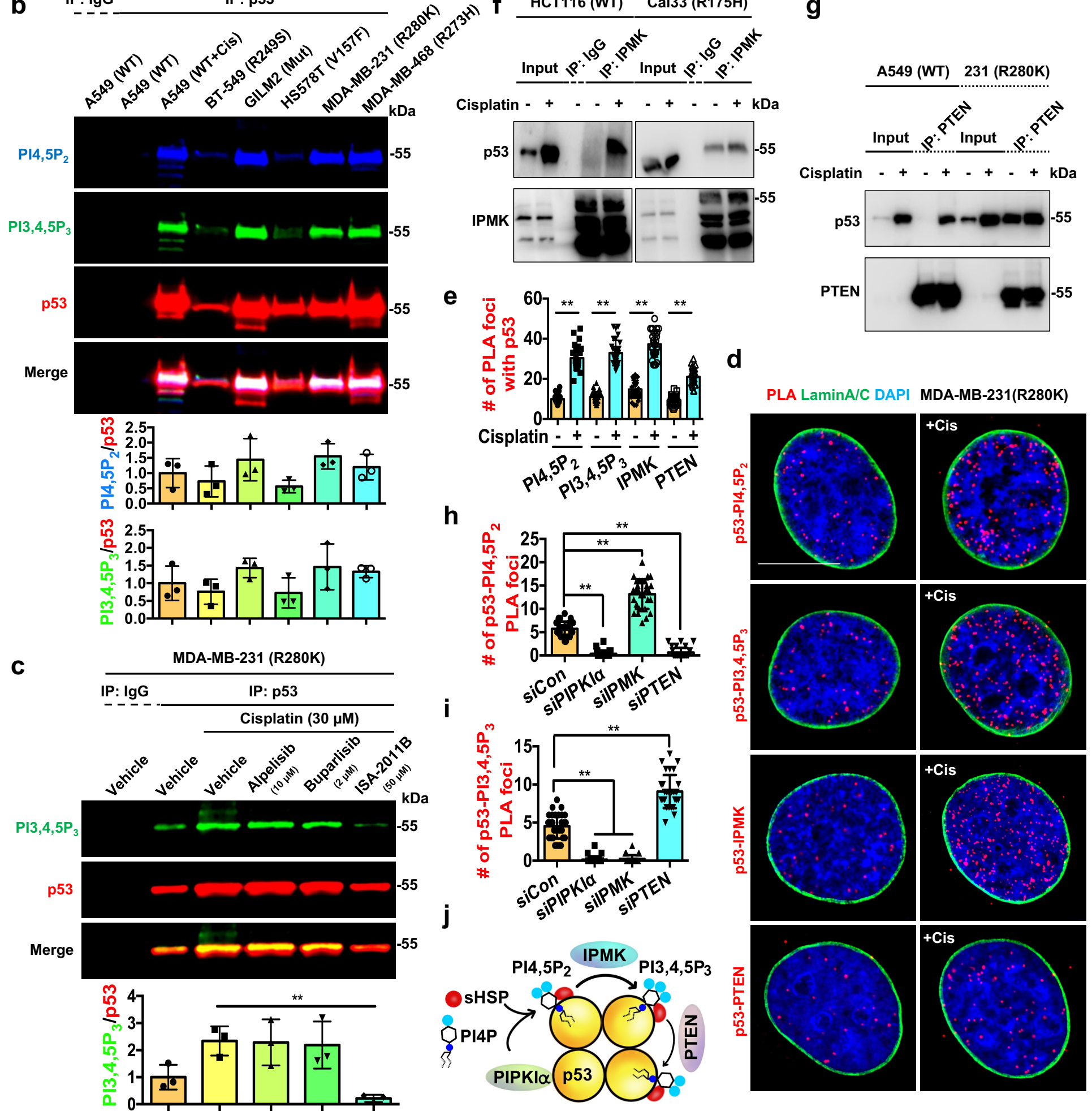


Fig. 5

a

MDA-MB-231 (R280K)

Input $\quad p \cdot 10^{0} \quad$ IP: p53

Cisplatin $\quad-\quad+\quad-\quad+\quad+\quad k D a$

$\mathrm{PI} 3,4,5 \mathrm{P}$
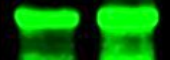

$-2$

p53

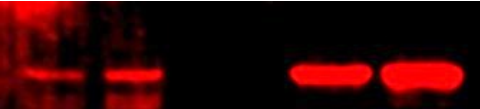

Merge

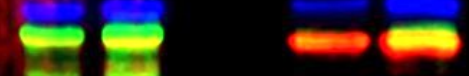

b

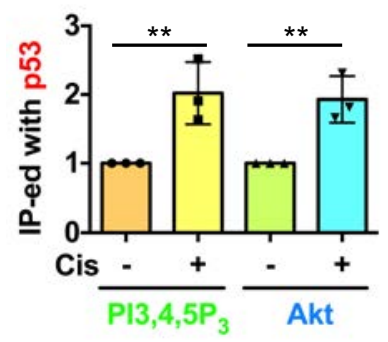

C

MDA-MB-231(R280K)

\begin{tabular}{|c|c|}
\hline IP: IgG & IP: Akt \\
\hline
\end{tabular}

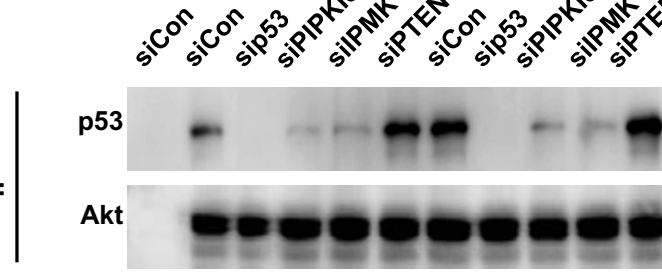
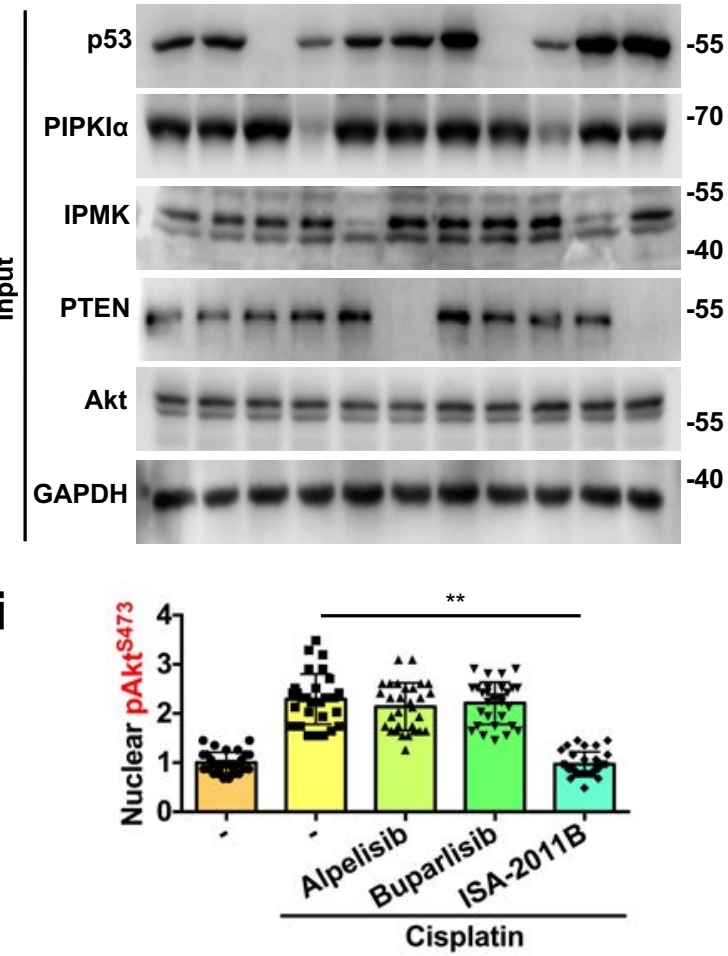
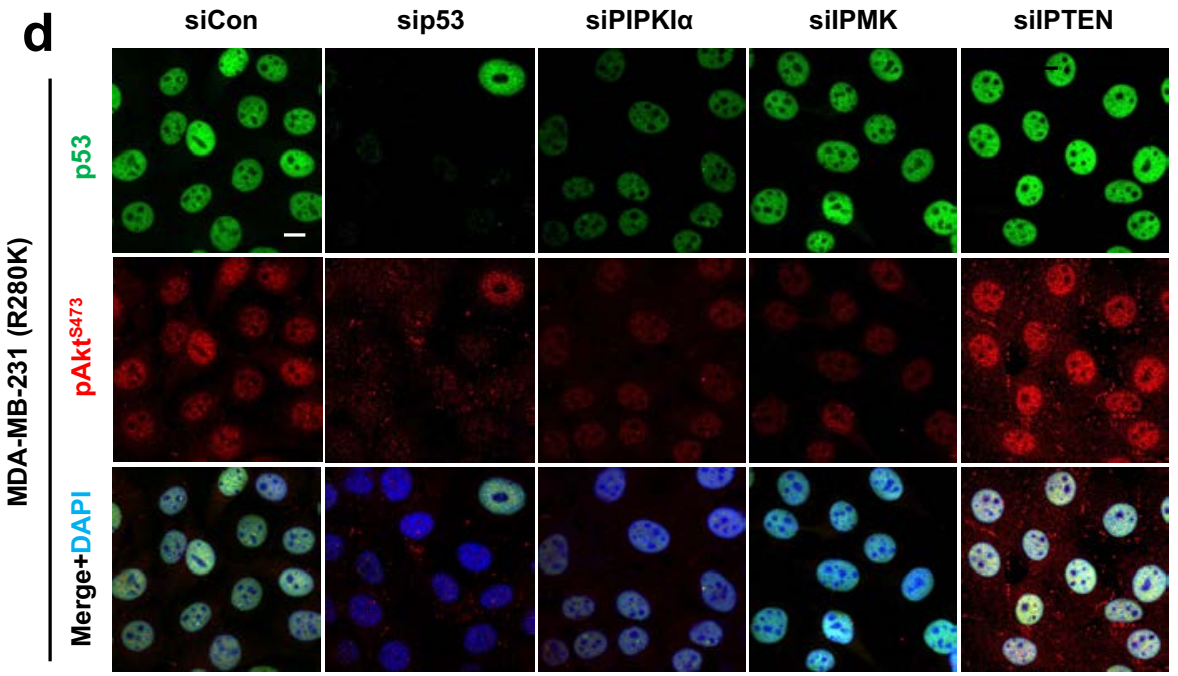

e

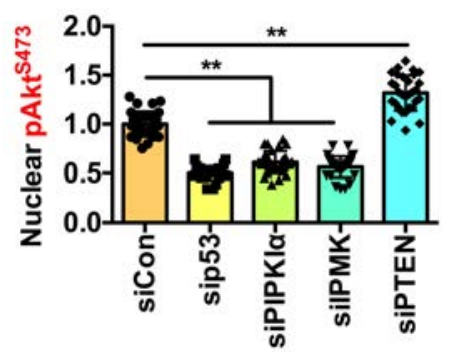

g

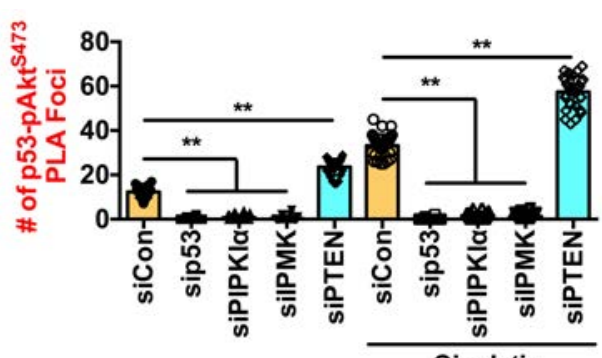

f

MDA-MB-231 (R280K)
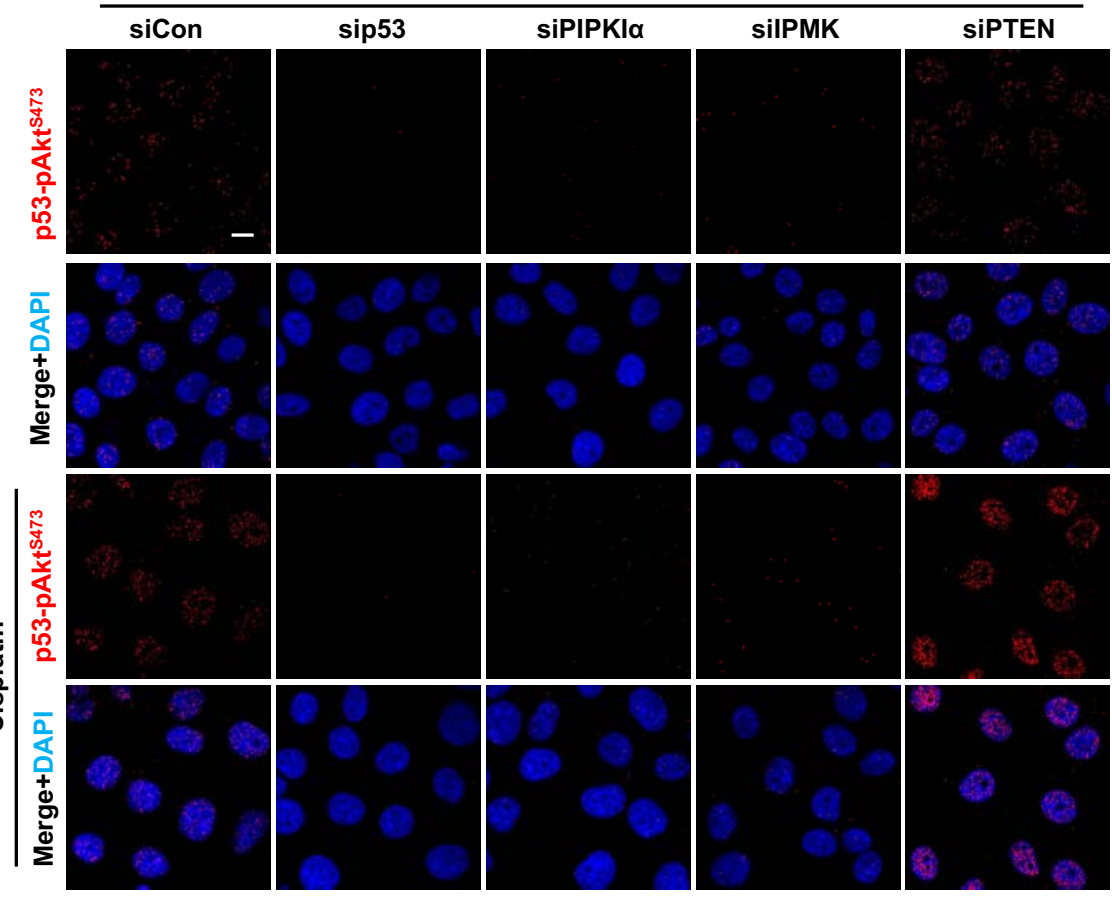

Cisplatin
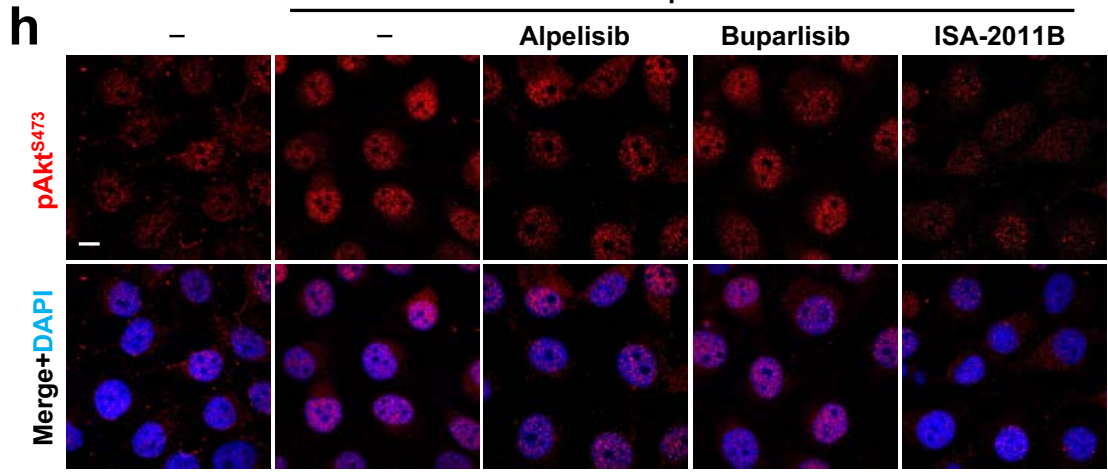
Fig. 6

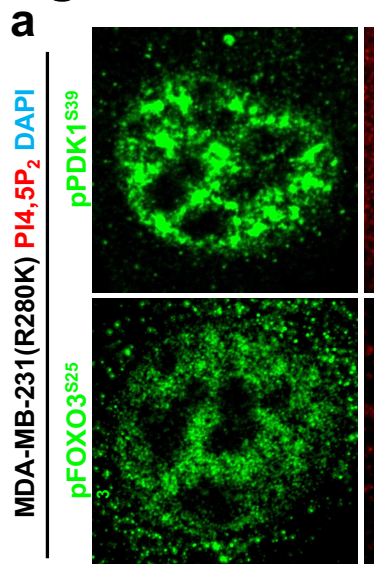

C
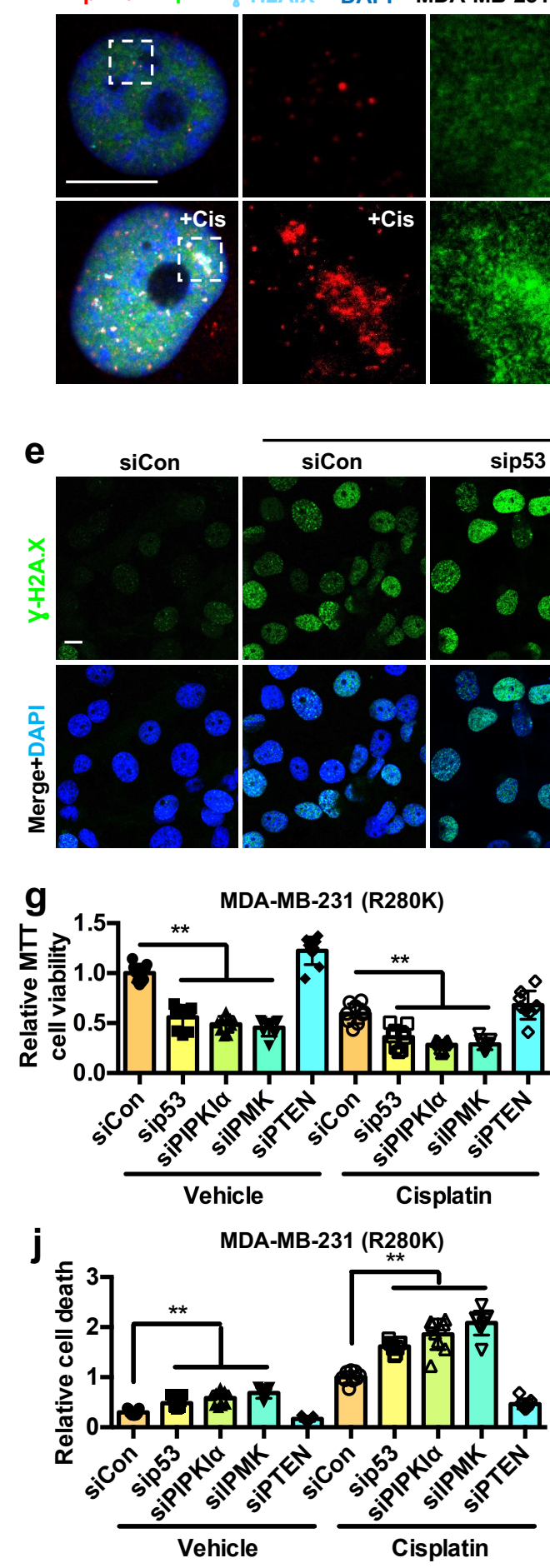

Cisplatin
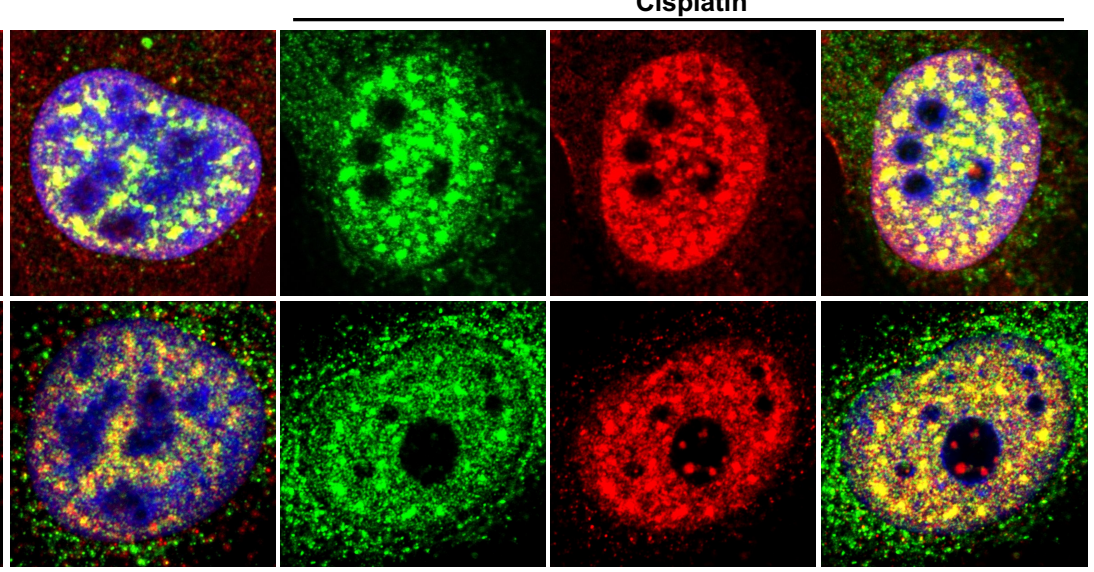

b

d

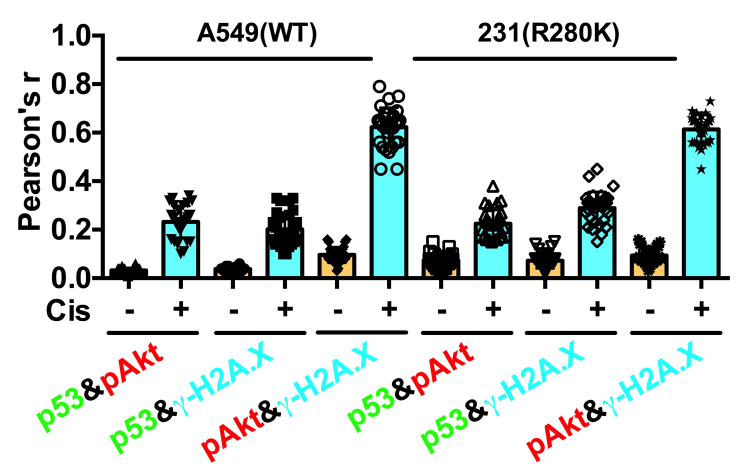

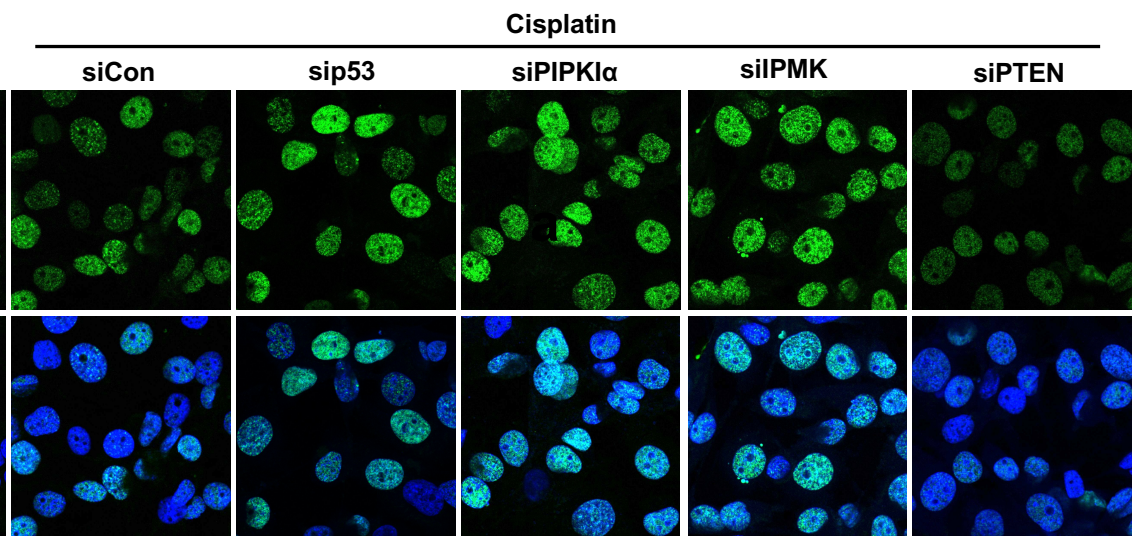

f MDA-MB-231 (R280K)



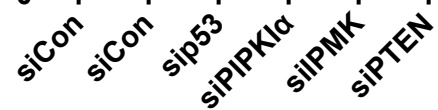

Cisplatin
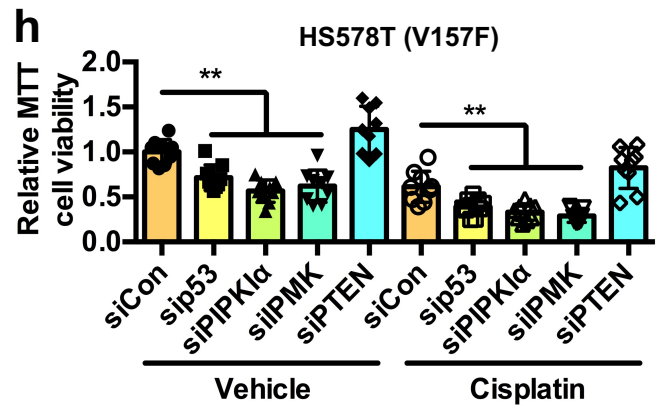

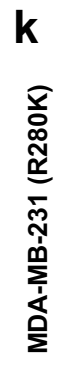

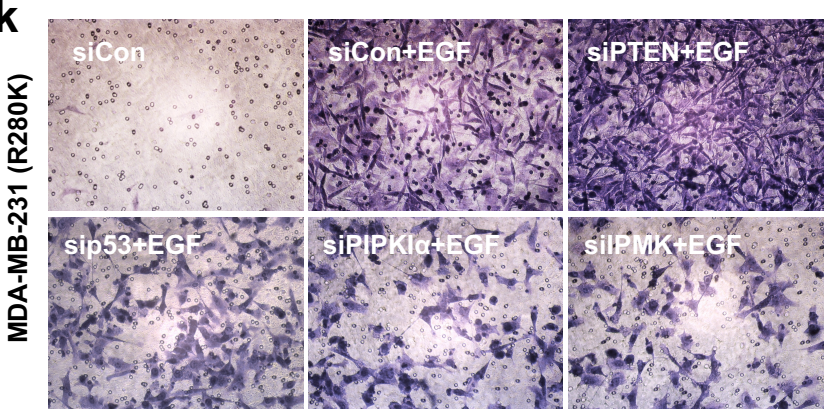

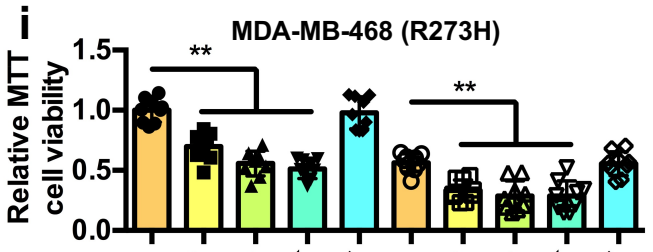

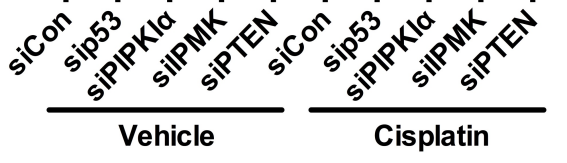

I

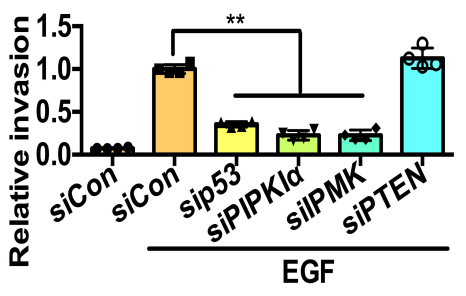


Fig. 7

a

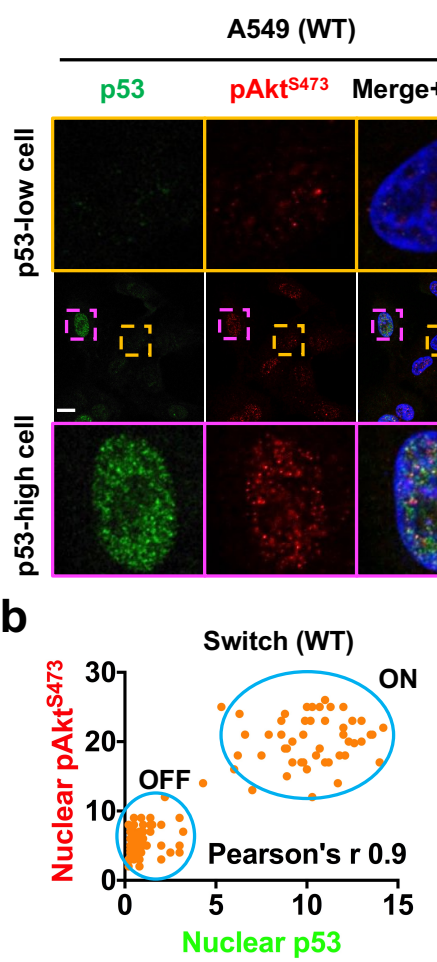

d

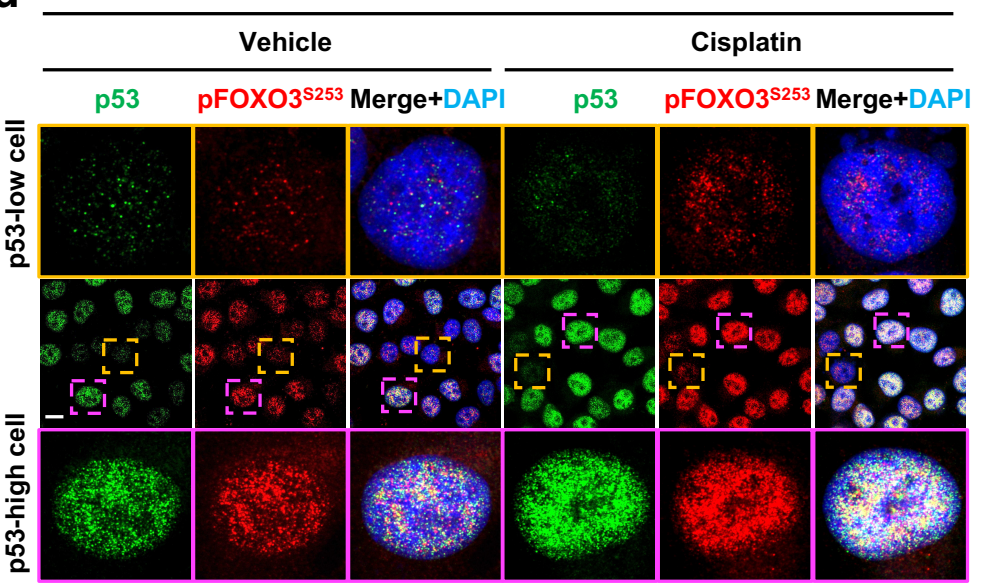

h
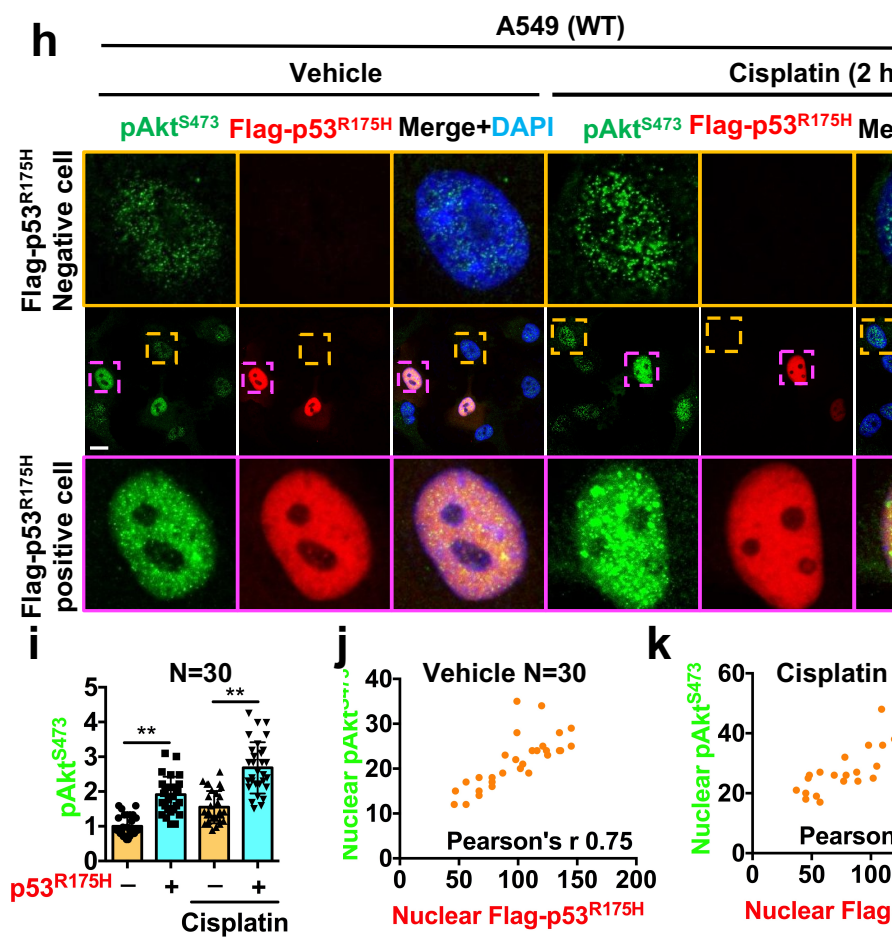

Cisplatin (2 h)

e
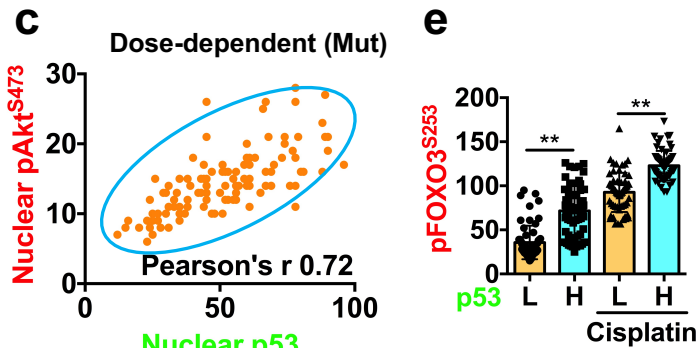

ag-p $53^{R 175 H}$ Merge+DAPI
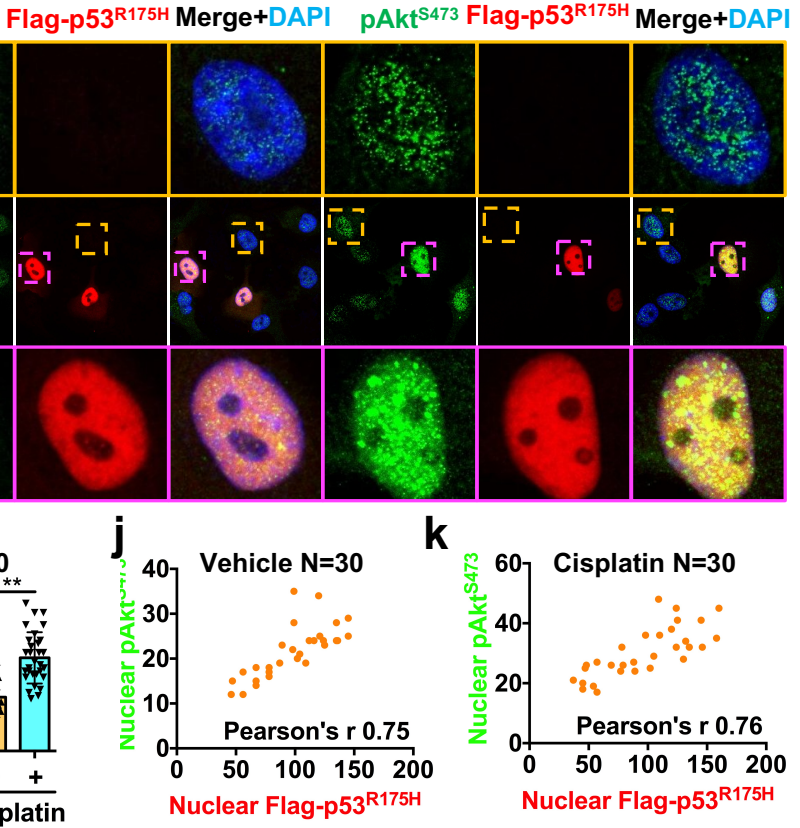


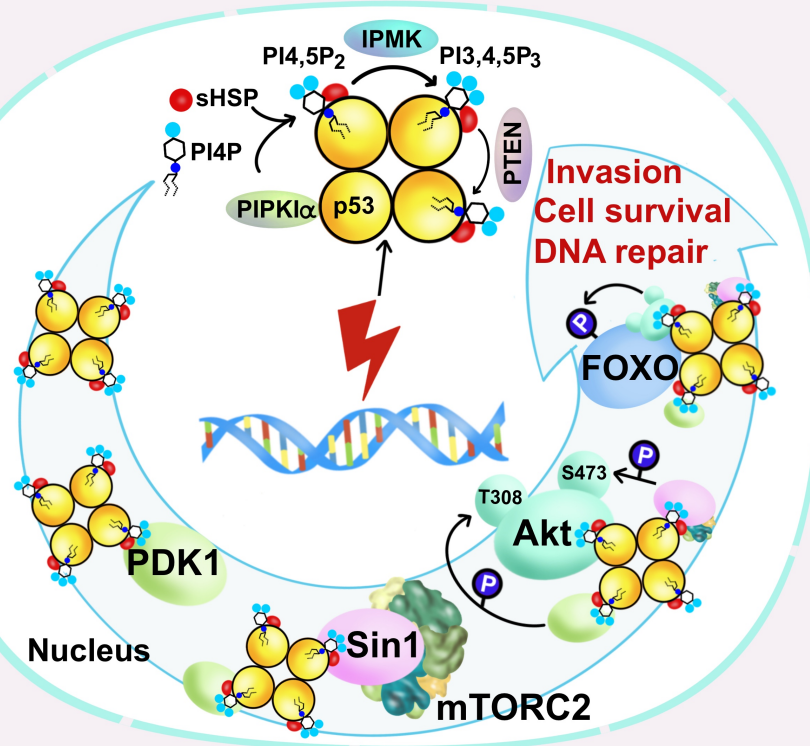

